\title{
Daclizumab: Development, Clinical Trials, and Practical Aspects of Use in Multiple Sclerosis
}

\author{
Laura E. Baldassari ${ }^{1} \cdot$ John W. Rose ${ }^{1}$
}

Published online: 13 July 2017

(C) The American Society for Experimental NeuroTherapeutics, Inc. 2017

\begin{abstract}
Daclizumab is a humanized monoclonal antibody directed towards CD25, the alpha subunit of the high-affinity interleukin (IL)-2 receptor. Daclizumab exerts its effects via multiple mechanisms, including reduction of IL-2-mediated lymphocyte activation and upregulation of CD56-bright natural killer cells. Intravenous daclizumab $\left(\right.$ Zenapax $\left.^{\mathrm{TM}}\right)$ was initially approved for prevention of rejection in renal transplant. In subsequent early testing, followed by larger-scale phase II and phase III trials, both intravenous and subcutaneous daclizumab have demonstrated clinical efficacy in the treatment of multiple sclerosis. The subcutaneous daclizumab prepared by high-yield process was utilized in the advanced phase II and phase III trials (SELECT and DECIDE). Highyield process daclizumab is now approved by the US Food and Drug Administration for relapsing-remitting multiple sclerosis, and is now formally termed daclizumab beta (DAC-beta; Zinbryta ${ }^{\mathrm{TM}}$ ). In this review, the early development of anti-IL-2 receptor alpha monoclonal antibodies and the properties of IL-2 and its receptor are discussed, and diverse mechanisms of action for daclizumab are presented. Results of the CHOICE, SELECT, and DECIDE clinical trials are discussed in detail. Adverse events observed in clinical trials included cutaneous reactions, liver enzyme elevations, infec-
\end{abstract}

Electronic supplementary material The online version of this article (doi:10.1007/s13311-017-0553-8) contains supplementary material, which is available to authorized users.

John W. Rose

jrose@genetics.utah.edu

1 Division of Neuroimmunology, Department of Neurology, University of Utah, Imaging and Neurosciences Center, 729 Arapeen Drive, Salt Lake City, UT 84108, USA tions, and autoimmune phenomena. DAC-beta is a monthly, patient-administered subcutaneous injection that requires enrollment in a safety monitoring (REMS) program for monthly liver function testing. Prescribers should be aware of the potential adverse events, as early recognition and management is important, particularly in cutaneous and hepatic reactions. Continued clinical experience with DAC-beta, including observations from the REMS program, will define its place in the armamentarium of immunotherapeutics for relapsingremitting multiple sclerosis.

Keywords Daclizumab · relapsing-remitting multiple sclerosis $\cdot$ monoclonal antibodies $\cdot$ interleukin-2 . interleukin-2 receptor $\cdot \mathrm{CD} 25$

\section{Introduction}

Daclizumab is an IgG1 monoclonal antibody (MAb) specific for the interleukin (IL)-2 receptor alpha (IL-2R $\alpha$ ) chain (CD25), and was the first US Food and Drug Administration (FDA)-approved humanized MAb for clinical use in 1997 [1]. Daclizumab has proven effective for relapsing-remitting multiple sclerosis (RRMS). IL-2 and IL-2R are thought to be important in the pathogenesis of MS, and daclizumab is the first therapy to block the binding of IL-2 to IL-2R $\alpha$. Increased availability of IL-2 for binding to IL-2R without the alpha chain contributes to the efficacy of daclizumab therapy [2-4]. Further details of the immunologic implications of this mechanism of action are discussed below. 


\section{Development and Preclinical Studies}

\section{IL-2 Properties}

IL-2 is a $15.5-\mathrm{kDa}$ proinflammatory cytokine discovered in supernatants in tissue culture fluid of mitogen-activated $\mathrm{T}$ cells; it is produced primarily by $\mathrm{CD} 4^{+} \mathrm{T}$ cells, and also by activated $\mathrm{CD} 8^{+} \mathrm{T}$ cells, dendritic cells, and natural killer (NK) cells [5-9]. This cytokine can support both Thelper (Th) 1 and Th2 differentiation, while inhibiting Th17 differentiation. However, IL-2 can support expansion of Th17 cells. IL-2 is essential for regulatory $\mathrm{T}$ cell (Treg cell) differentiation and survival. IL-2 is involved in activation of immune responses, as well as control of autoimmunity and inflammation, and is therefore considered a pleotropic cytokine. There is considerable therapeutic potential for IL-2 in treatment of malignancies and at a low dose for control of autoimmune diseases [6].

\section{Discovery of IL-2R}

The identification of a T-cell activation antigen termed TAC led to the discovery of the IL-2R alpha chain (CD25) [10-14]. The initial TAC-specific MAb (anti-TAC) developed by Uchiyama was found to bind to a $55-\mathrm{kDa}$ transmembrane protein, which was the first of 3 proteins to be identified as the high affinity IL$2 \mathrm{R}[5,14,15]$. The subsequent identification of the $70-\mathrm{kDa} \mathrm{IL}-$ $2 \mathrm{R}$ beta chain (CD122) and the 64-kDa gamma chain (CD132) completed the components of the high affinity IL-2R. The IL-2R beta chain is shared with the IL-15R (Table 1). The gamma chain is shared with receptors for IL-4, IL-7, IL-9, IL-15, and IL-21 [5]. The gamma chain is essential for activation of Janus kinase/ signal transducer and activator of transcription and other pathways, which in different combinations can provide signals for growth, survival, death, or differentiation $[5,15]$.

\section{IL-2R Structure and Function}

There are 3 forms of the IL-2R. The high-affinity receptor for IL-2 incorporates all three chains $(\alpha, \beta$, and $\gamma)$ and is present on activated T cells, activated B cells, and Treg cells. An intermediate-affinity receptor consists of the gamma and beta chains only, and is expressed on NK cells, as well as resting T and $\mathrm{B}$ cells. The low-affinity receptor consists of the alpha chain and is expressed on dendritic cells. Therefore, MAbs targeting the alpha chain of the IL-2R will bind to the highand low-affinity forms of the receptor but not the intermediate form (Table 1) [16].

\section{IL-2R-Specific Immunotherapies in Experimental Autoimmune Encephalomyelitis}

Experimental therapies targeting the IL-2R with $\mathrm{mAbs}$ and chimeric immunotoxins are, respectively, capable of
Table 1 Interleukin-2 receptors

\begin{tabular}{|c|c|c|}
\hline Type & Composition & Distribution \\
\hline High affinity & $\begin{array}{l}\text { Alpha, beta, and gamma } \\
\text { chains }\end{array}$ & $\begin{array}{l}\text { Activated } \mathrm{T} \text { and } \mathrm{B} \\
\text { cells } \\
\text { Including Tregs }\end{array}$ \\
\hline $\begin{array}{l}\text { Intermediate } \\
\text { affinity }\end{array}$ & Beta and gamma chains & NK cells \\
\hline Low affinity & Alpha chain & Dendritic cells \\
\hline
\end{tabular}

Treg = regulatory $\mathrm{T}$ cells; $\mathrm{NK}=$ natural killer

inhibiting or ablating experimental autoimmune encephalomyelitis (Fig. 1) [17]. Subsequent studies of anti-IL-2R therapy with immunotoxins have demonstrated that they are effective during induction and at onset of experimental autoimmune encephalomyelitis; however, treatment during more active disease increased severity of clinical signs [18].

\section{Effects of Early Anti-TAC Antibodies in Neoplastic Disease}

Xenogenic anti-TAC mAb therapy for leukemia was successful but was limited by formation of human antimurine antibodies [13]. For continual administration, a new approach would be required; therefore, humanization of the MAb was of interest.

\section{Development of Humanized mAb Specific for CD25}

The concept of humanization was proposed by Jones et al. in 1986 [19]. The development of humanized mAbs was pursued to reduce immunogenicity by recombinant engineering of the variable chains of therapeutic mAbs. Thus, the humanized $\mathrm{mAb}$ would be potentially less immunogenic than chimeric mAbs. This was accomplished by including only the complementarity-determining regions from the original xenogenic mAb: anti-TAC. The detailed methodology for grafting the engineered complementarity-determining regions into human mAbs was developed at Protein Design Labs by Queen et al. [20]. Daclizumab was the first humanized mAbs to be approved by the FDA.

\section{Daclizumab Therapy in Transplant Medicine, Uveitis, and Human T-Lymphotropic Virus-1-Associated Transverse Myelitis}

Daclizumab was originally approved by the FDA in 1997 for renal transplant rejection prevention. The therapy was utilized in patients not responding to standard immunotherapy at the time [21]. Daclizumab treatment for uveitis was pioneered at the National Eye Institute. Efficacy for noninfectious causes of uveitis was investigated for multiple etiologies, including sarcoidosis. Though effectiveness was reported in 6 patients 
Fig. 1 Effects of interleukin (IL) 2-toxin (IL-2 PE40) on adoptively transferred experimental autoimmune encephalomyelitis (EAE). (A, C) Mice treated with phosphate-buffered saline (PBS) developed relapsing-remitting EAE with marked clinical impairment and striking demyelination. (B, D) Mice treated with IL2 toxin did not develop EAE, were clinically normal, and demonstrated no demyelination [15]
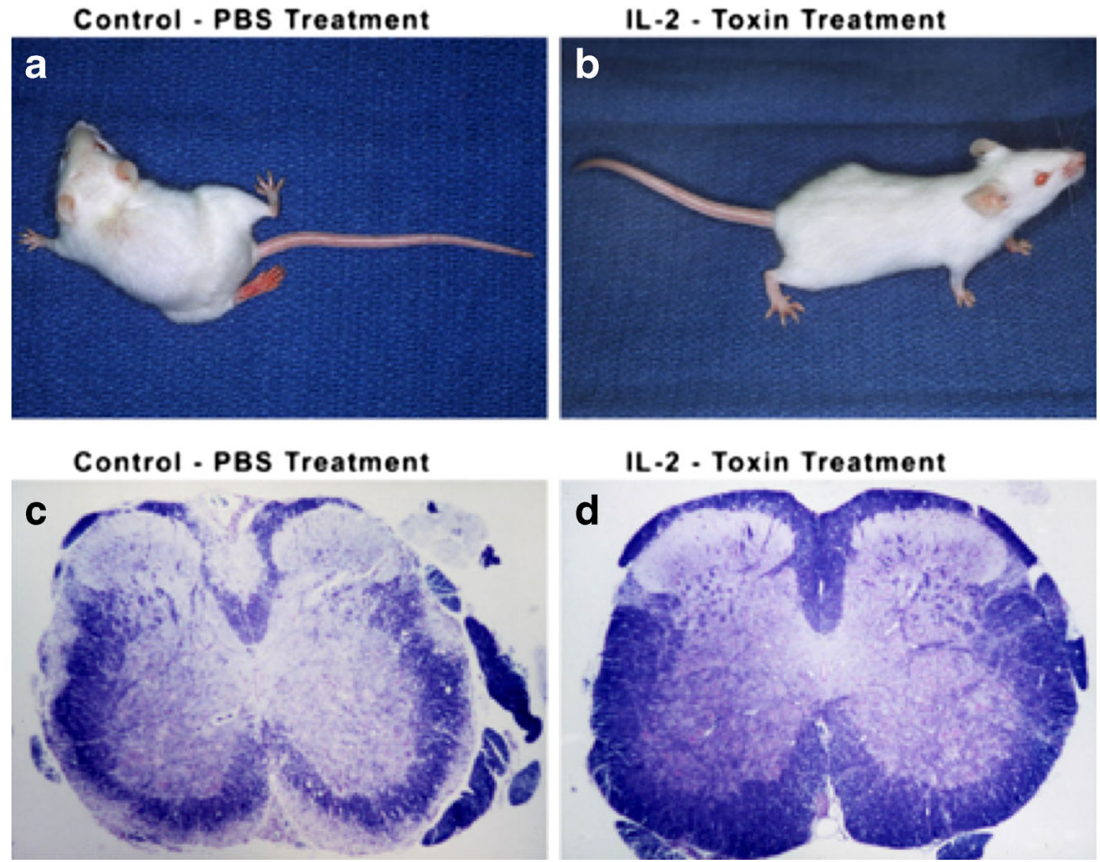

with inflammatory uveitis, these studies were small and potentially confounded by complicated therapeutic regimens that limit conclusions regarding the effectiveness of subcutaneous daclizumab monotherapy [22-24]. A trial of daclizumab therapy in human T-lymphotropic virus-I/II myelopathy was reported by Lehky et al. [25], and results indicated reduction in proviral load and spontaneous lymphoproliferation.

\section{Early Clinical Trials in MS}

Initial studies evaluated the combination of intravenous daclizumab (Zenapax ${ }^{\mathrm{TM}}$ ) and interferon (IFN)- $\beta$ [26].
Improved clinical status and reduction in active lesion formation were readily apparent in these investigations. Subsequent open-label intravenous daclizumab use suggested the potential of clinical efficacy as a monotherapy (Fig. 2) [27].

Early phase II studies evaluated intravenous daclizumab as add-on therapy to ongoing IFN- $\beta$ therapy for patients with RRMS with clinically active disease and substantial magnetic resonance imaging (MRI) activity, utilizing a protocol designed by Martin and Bielekova at the National Institutes of Health $[26,28]$. This protocol involved monthly administration of intravenous daclizumab in combination with IFN- $\beta$. The patients were evaluated with clinical scores and contrastenhanced MRIs on a monthly basis during a 3-month
Fig. 2 Example of patient magnetic resonance imaging (MRI) from early intravenous daclizumab trial. MRI predaclizumab and 6 months postdaclizumab intravenous monotherapy in a patient with aggressive relapsing-remitting multiple sclerosis not responding to multiple previous therapies. There is a marked reduction of (A, D) contrast-enhancing lesions with regression of lesions in the $(\mathrm{B}, \mathrm{E})$ cerebral hemispheres and (C, F) brainstem [25]
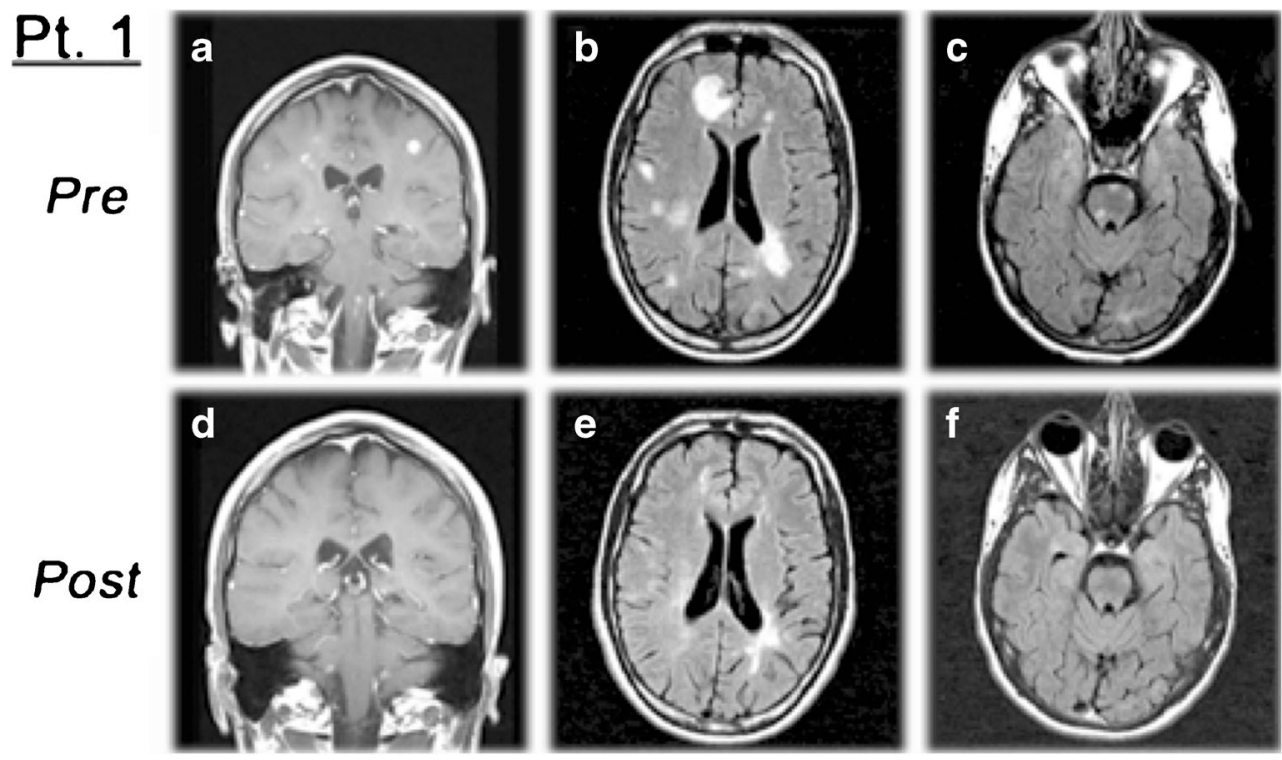
pretreatment period, at baseline, 2 weeks after initial treatment, and then monthly thereafter. At the time point of 5.5 months, if the patient was free of clinical and MRI activity, they were transferred to intravenous daclizumab monotherapy; however, if there was continued disease activity and/or MRI activity then the dose of intravenous daclizumab was increased and IFN- $\beta$ was continued. These investigations demonstrated significant reductions in relapse rates, number of contrast-enhancing lesions, as well as improvement on clinical rating scales, including the Ambulation Index, the Scripps Neurologic Rating Scale, and the Kurtzke Expanded Disability Status Scale [26, 28].

Extended utilization, efficacy, and side effects of intravenous daclizumab in treatment of RRMS seen in small early clinical trials demonstrated that the medication appeared effective over years of treatment, and side effects included rash and lymphadenopathy [29]. Additionally, a retrospective review of open-label intravenous daclizumab use suggested side effects potentially including lymphadenopathy, diffuse rash, and breast nodules [30]. Overall, these early investigations of intravenous daclizumab in RRMS appeared promising and provided the impetus for larger pivotal trials.

\section{Mechanism of Action}

Daclizumab was initially developed to prevent the binding of IL-2 to the high-affinity IL-2 receptor that is expressed on activated lymphocytes by binding IL-2R $\alpha$ (CD25). Therefore, the original therapeutic intent of daclizumab was to block the binding of IL-2 to the high-affinity IL-2R, thereby interfering with the activation and expansion of $\mathrm{T}$ cells mediated by IL-2. However, this effect is not as strong as projected during in vitro testing [2-4,31]. As a result, further investigations have revealed several other important effects of daclizumab on the immune system that are of great interest regarding its therapeutic effects in MS.

In addition to this primary action of binding the CD25 subunit of the high-affinity IL-2R, the other major effects of daclizumab on the immune system include upregulation of CD56-bright NK cells, decreasing early T-cell activation via blockade of IL-2 trans-presentation by dendritic cells, direct effects on both effector and Treg cells, and reduction of lymphoid inducer T cells (LTIs) [9, 32]. These mechanisms are discussed in further detail below, and overall are felt to augment mechanisms of immune tolerance and therefore potentially improve immune system dysregulation underlying autoimmune disease, particularly in MS [32].

NK cells are lymphocytes involved in the adaptive immune response, as well as response to tumors and viruses. A subset of NK cells is referred to CD56-bright NK cells, which are considered to have primarily regulatory and surveillance functions. Daclizumab has been shown to upregulate CD56-bright
NK cells in number and function, likely via increased availability of IL-2 for binding to the intermediate-affinity IL-2R found on these cells [33-35]. IL-2 production by activated T cells is increased in the setting of IL- $2 \mathrm{R} \alpha$ subunit blockade and therefore results in increased locally available IL2 that is no longer able to bind to the high-affinity IL-2R on $\mathrm{T}$ cells $[32,36]$.

This expansion of CD56-bright NK cells has several effects given their immunoregulatory role, particularly for $\mathrm{T}$ cells. The regulatory function of CD56-bright NK cells becomes increasingly important in the setting of daclizumab use, as traditional Treg cells are inhibited by daclizumab [37, 38]. CD56-bright NK cells isolated from patients on daclizumab have demonstrated increased cytotoxicity towards autoreactive T cells ex vivo; studies have also demonstrated a correlation between CD56-bright NK cell expansion and reduction of $\mathrm{T}$ cells in patients receiving daclizumab, suggestive of an in vivo effect as well $[32,33,36]$. Another important mechanism of this enhanced cytotoxicity is the upregulation of granzyme $\mathrm{K}$, a serine protease expressed in cytotoxic granules of NK cells that induces apoptosis in target cells, in patients treated with daclizumab [39]. Therefore, the upregulation of CD56-bright NK cells with subsequent regulation of T cells is an important effect of daclizumab.

Further investigations into the mechanisms of action of daclizumab revealed effects on dendritic cells [32]. Activated dendritic cells express the IL-2R alpha subunit and secrete IL-2 following antigen stimulation; these cells then interact with early $\mathrm{T}$ cells, which express the intermediate-affinity IL-2R containing beta and gamma subunits. The alpha subunit on the dendritic cell interacts with the beta and gamma subunits on the $\mathrm{T}$ cell, which is a process referred to as trans-presentation of IL-2. Subsequently, the T cell is stimulated and expresses the IL-2R alpha subunit, which propagates $\mathrm{T}$-cell proliferation and activation. Daclizumab binds to the IL-2R alpha subunit on dendritic cells, inhibiting trans-presentation of IL-2 and reducing further T-cell activation and proliferation [40, 41].

As mentioned above, daclizumab has direct effects upon Treg cells [37, 38]. Reduction in Treg cells can have beneficial effects including increased cancer surveillance and pathogen immunity, but concern is also raised regarding autoimmunity in this setting. However, studies of patients receiving daclizumab have indicated that the reduction in Treg cells is not necessarily associated with adverse events, despite reports of autoimmune phenomena in clinical studies. It has been suggested that Tregs can continue to function in the setting of low levels of IL-2, which may help mitigate risks of autoimmunity associated with impaired IL-2 signaling in the setting of daclizumab use [32, 42].

Daclizumab is thought to have direct effects on effector T cells as well. In addition to downregulatory effects on effector $\mathrm{T}$ cells via upregulation of CD56-bright NK cells and 
inhibition of IL-2 trans-presentation by dendritic cells, there is evidence that daclizumab can, to some degree, directly inhibit $\mathrm{CD} 4^{+} / \mathrm{CD} 25^{+}$effector $\mathrm{T}$ cells [43].

Daclizumab also inhibits the formation of LTIs, which have been implicated as initiators of central nervous system pathology in MS via their ability to form meningeal follicles and subsequently result in cortical inflammation $[44,45]$. Additionally, patients with MS have higher numbers of LTIs than healthy controls, but these levels are reduced with daclizumab treatment [44]. Studies have also shown an association of decreased LTIs with increased CD56-bright NK cells, which is interesting from the mechanistic perspective as the 2 cell types have a common $\mathrm{CD} 34^{+}$precursor; it is thought that increased bioavailable IL-2 shifts the differentiation of this common precursor to CD56-bright NK cells rather than LTIs [32, 44]. However, investigation of daclizumab therapy did not find an altered the number of circulating LTIs or their subsets [46].

From a mechanistic perspective, it is important to note that the FDA-approved formulation of subcutaneous daclizumab, daclizumab beta differs from the original humanized form of the mAb in terms of the extent of glycosylation. This alteration in glycosylation has resulted in significantly reduced antibody dependent cell-mediated cytotoxicity [4]. The implications of this change in terms of $\mathrm{mAb}$ function in MS is unknown, and could be an important point for investigation in the future. MS trials have used 3 different forms of daclizumab: intravenous daclizumab (DAC-IV; Zenapax ${ }^{\mathrm{TM}}$ ), subcutaneous daclizumab formulation 1 (DAC-SQ1; Penzberg), and daclizumab beta (DAC- $\beta$; Zinbryta $^{\mathrm{TM}}$ ) (Table 2) [4].

\section{Pivotal Clinical Trials}

Daclizumab has been evaluated in 3 major clinical trials that will be discussed in detail below: the CHOICE, SELECT, and DECIDE trials. Study methods, as well as primary and secondary outcomes, are summarized in Table 3.

Table 2 Daclizumab formulations in multiple sclerosis clinical trials

\begin{tabular}{|c|c|}
\hline Preparation & Trial \\
\hline Daclizumab IV (Zenapax ${ }^{\mathrm{TM}}$ ) & $\begin{array}{l}\text { Open-label, early phase I/II } \\
\text { trials }\end{array}$ \\
\hline Daclizumab SC (Penzberg, SQ1) & CHOICE trial \\
\hline $\begin{array}{l}\text { Daclizumab beta SC (DAC-HYP; } \\
\text { Zinbryta }^{\mathrm{TM}} \text { ) }\end{array}$ & SELECT and DECIDE trials \\
\hline
\end{tabular}

$\mathrm{IV}=$ intravenous; $\mathrm{SC}=$ subcutaneous; $\mathrm{DAC}-\mathrm{HYP}=$ daclizumab highyield process

\section{Clinical Efficacy}

The first pivotal clinical trial of daclizumab in MS was the CHOICE study (ClinicalTrials.gov, NCT00109161), in which the DAC-SQ1 formulation was utilized (Table 2) [47]. The CHOICE study was a phase II, randomized, double-blind, placebo-controlled multicenter trial that compared daclizumab (DAC-SQ1) with IFN- $\beta-1 \mathrm{a}$ (Avonex) in patients with either relapsing-remitting or secondary progressive MS [47]. Participants $(n=230)$ who were previously taking IFN- $\beta$ (either $\beta$-1a i.m., $\beta$-1a s.c., or $\beta$-1b s.c.) were randomized to receive either add-on high-dose DAC-SQ1 ( $2 \mathrm{mg} / \mathrm{kg}$ every 2 weeks; $n=75)$, add-on low dose DAC-SQ1 ( $1 \mathrm{mg} / \mathrm{kg}$ every 4 weeks; $n=78)$, or IFN- $\beta-1$ and placebo $(n=77)$ for a period of 24 weeks. Patients were followed for an additional 48 weeks for safety and clinical monitoring. Patients enrolled in the CHOICE study were predominantly female (26\% male), white (92\%), had RRMS (92\% vs $8 \%$ secondary progressive), and had an average of 2.5 relapses over the preceding 2 years.

Although the primary endpoint was based on imaging, several clinical secondary endpoints were assessed. Details regarding the study's primary outcome measures are presented in the "Imaging Endpoints" section. Secondary outcomes of this initial, short-term phase II clinical trial included both unadjusted and adjusted (for number of relapses in prior 2 years and baseline disease status) annualized relapse rates (ARR) among the 3 treatment groups (IFN/placebo, IFN/low-dose DAC-SQ1, and IFN/high-dose DAC-SQ1). The unadjusted ARR in the IFN/placebo group was 0.86 versus 0.49 in the IFN/high-dose DAC-SQ1 group [43\% difference, 95\% confidence interval $(\mathrm{CI})-28$ to $74 \%(p=0.18)]$, and 0.58 in the IFN/low-dose DAC-SQ1 group (32\% difference, 95\% CI - 45 to $69 ; p=0.31$ ). Similarly, no significant differences between the high- and low-dose DAC-SQ1/IFN groups and the IFN/ placebo groups were noted upon adjustment of the ARR for baseline disease activity. No significant changes were found in median changes in Expanded Disability Status Scale (EDSS) or Multiple Sclerosis Functional Composite-3 scores between baseline and week 24 among the 3 treatment groups.

Following completion of treatment in the CHOICE study, patients were followed for an additional 48 weeks for safety, imaging, and clinical monitoring. At the end of this period, there was no statistically significant difference in the proportion of patients who had relapses among the 3 groups (45\% of IFN/placebo group, 53\% of IFN/low-dose DAC-SQ1 group, and $48 \%$ in IFN/high-dose DAC-SQ1 group; $p=0.67$ ).

The SELECT trial was a phase II multicenter study completed in 2010, and differed from the CHOICE study in that patients $(n=621)$ were randomized to receive either placebo $(n=204)$, Daclizumab high-yield process (DAC-HYP, now referred to as DAC- $\beta) 150 \mathrm{mg}(n=208)$ or $300 \mathrm{mg}(n=$ 209) every 4 weeks for 52 weeks (ClinicalTrials.gov, NCT00390221) [48]. Additionally, the SELECT trial only 
Table 3 Review of daclizumab (DAC) clinical trial methods and results

\begin{tabular}{|c|c|c|c|}
\hline & CHOICE $(n=230)$ & $\operatorname{SELECT}(n=621)$ & $\operatorname{DECIDE}(n=1841)$ \\
\hline $\begin{array}{l}\text { DAC } \\
\text { dose/regimen }\end{array}$ & $\begin{array}{l}\text { DAC-SQ1 } 2 \mathrm{mg} / \mathrm{kg} \text { s.c. every } 2 \text { weeks } \\
\text { (high-dose) or daclizumab } 1 \mathrm{mg} / \mathrm{kg} \text { s.c. } \\
\text { every } 4 \text { weeks (low dose) }\end{array}$ & $\begin{array}{l}\text { DAC- } \beta 150 \mathrm{mg} \text { or } 300 \mathrm{mg} \text { s.c. every } \\
\quad 4 \text { weeks }\end{array}$ & DAC- $\beta 150 \mathrm{mg}$ s.c. every 4 weeks \\
\hline Comparator & IFN- $\beta 1$ a (add-on), placebo & Placebo & IFN- $\beta 1 \mathrm{a}$ (Avonex) \\
\hline Duration of trial & $\begin{array}{l}24 \text { weeks of treatment, } 96 \text { total weeks of } \\
\text { follow-up }\end{array}$ & 52 weeks & 144 weeks \\
\hline Primary endpoint & $\begin{array}{l}\text { Adjusted mean number of new or } \\
\text { enlarging gadolinium enhancing } \\
\text { lesions at } 24 \text { weeks: } 1) \text { IFN/placebo: } \\
4.75 \text { lesions; } 2) \text { IFN/low-dose } \\
\text { DAC-SQ1: } 3.58 \text { lesions }(p=0.51) ; 3) \\
\text { IFN/high-dose DAC-SQ1: } 1.32 \text { lesions } \\
(p=0.004)\end{array}$ & $\begin{array}{l}\text { ARR } 0.21 \text { for } 150 \mathrm{mg} \text { DAC- } \beta, 0.23 \text { for } \\
300 \mathrm{mg} \text { DAC, } 0.46 \text { for placebo }\end{array}$ & $\begin{array}{l}\text { ARR } 0.22 \text { in DAC- } \beta \text { vs } 0.39 \text { in IFN } \\
\quad(p<0.001)\end{array}$ \\
\hline $\begin{array}{l}\text { Secondary/tertiary } \\
\text { clinical } \\
\text { endpoints }\end{array}$ & $\begin{array}{l}\text { Unadjusted ARR: 1) IFN/placebo: } 0.86 ; \\
\text { 2) IFN/low-dose DAC-SQ1: } 0.58 \\
(p=0.31) ; 3) \text { IFN/high-dose } \\
\text { DAC-SQ1: } 0.49(p=0.18) \\
\text { Adjusted ARR: 1) IFN/placebo: } 0.41 ; 2) \\
\text { IFN/low-dose DAC-SQ1: } 0.29 \\
(p=0.35) ; 3) \text { IFN/high-dose } \\
\text { DAC-SQ1: } 0.27(p=0.30)\end{array}$ & $\begin{array}{l}\text { Estimated proportion of patients with } \\
\text { relapse at } 52 \text { weeks: } 1) 19 \% \text { in DAC- } \beta \\
150 \mathrm{mg}(p<0.001 \text { vs placebo); } 2) 20 \% \\
\text { in DAC- } \beta 300 \mathrm{mg} ; 3) 36 \% \text { in placebo } \\
\text { Estimated proportion of patients with } \\
\quad \text { disability progression at } 52 \text { weeks } \\
\text { (measured by EDSS): } 1) 6 \% \text { in DAC- } \beta \\
150 \mathrm{mg} \text { (HR } 0.43, p=0.21 \text { s placebo); } \\
\text { 2) } 8 \% \text { in DAC- } \beta 300 \mathrm{mg} ; 3) 13 \% \text { in } \\
\text { placebo }\end{array}$ & $\begin{array}{l}\text { Disability progression over } 144 \text { weeks } \\
\text { (measured by EDSS): } 1 \text { ) } 20 \% \text { in IFN } v s \\
16 \% \text { in DAC- } \beta ; 2) \text { HR } 0.85(95 \% \text { CI } \\
0.66-1.07 ; p=0.16)\end{array}$ \\
\hline $\begin{array}{l}\text { Secondary } \\
\text { imaging } \\
\text { endpoints }\end{array}$ & NA & $\begin{array}{l}\text { Cumulative number of new Gd-enhancing } \\
\text { lesions on MRI done every } 4 \text { weeks } \\
\text { between weeks } 8 \text { and } 24 \text { in some pa- } \\
\text { tients (frequent MRI subset): } 1) 1.5 \text { in } \\
\text { DAC- } \beta 150 \mathrm{mg}(p<0.001 \text { vs placebo); } \\
\text { 2) } 1.0 \text { in DAC- } \beta 300 \mathrm{mg} ; 3) 4.8 \text { in } \\
\text { placebo } \\
\text { Number of new or enlarged T2 lesions } \\
\text { between baseline and week 52: 1) } 2.4 \text { in } \\
\text { DAC- } \beta 150 \mathrm{mg}(p<0.001 \text { vs placebo); } \\
\text { 2) } 1.7 \text { in DAC- } \beta 300 \mathrm{mg} ; 3) 8.1 \text { in } \\
\text { placebo }\end{array}$ & $\begin{array}{l}\text { New or enlarged T2 lesions on MRI over } \\
96 \text { weeks: 1) } 9.4(95 \% \text { CI } 8.5-10.5) \text { in } \\
\text { IFN; } 2) 4.3(95 \% \text { CI } 3.9-4.8) \text { in } \\
\text { DAC- } \beta ; 3) 54 \% \text { reduction }(95 \% \text { CI } \\
47-61) \text { in DAC- } \beta \text { vs IFN }(p<0.001)\end{array}$ \\
\hline
\end{tabular}

$\mathrm{IFN}=$ interferon; $\mathrm{ARR}=$ annualized relapse rate; $\mathrm{EDSS}=$ Expanded Disability Status Scale; $\mathrm{HR}=$ hazard ratio; $\mathrm{CI}=$ confidence interval; $\mathrm{NA}=$ not applicable; $\mathrm{Gd}=$ gadolinium; $\mathrm{MRI}=$ magnetic resonance imaging

included patients with RRMS, whereas the CHOICE study permitted inclusion of patients with secondary progressive MS. Patients were predominantly female $(65 \%)$ and white $(96 \%)$, and $76 \%$ had not previously received diseasemodifying therapy for MS. Additionally, $43 \%$ of patients had at least 1 contrast-enhancing lesion at baseline. The primary endpoint was the ARR, which was adjusted for the number of relapses in the year preceding entry into the study, baseline EDSS $(\leq 2.5$ or $>2.5)$, and baseline age $(\leq 35$ or $>$ 35 years). At study completion, the ARR was 0.46 [95\% confidence interval (CI) 0.37-0.57) for placebo, 0.21 (95\% CI $0.16-0.29$ ) for DAC- $\beta 150 \mathrm{mg}$, and 0.23 (95\% CI $0.17-$ 0.31 ) for DAC- $\beta 300 \mathrm{mg}$. Compared with placebo, there was a $54 \%$ reduction in the ARR $(95 \%$ CI $33-68$; $p<0.0001)$ with DAC- $\beta 150 \mathrm{mg}$, and a $50 \%$ reduction in the ARR (95\% CI 28-65; $p=0.00015)$ with DAC- $\beta 300 \mathrm{mg}$.

In terms of secondary endpoints, the SELECT trial examined the estimated proportion of patients with relapse at 52 weeks.
Compared with $36 \%$ of patients on placebo $(n=69 / 196), 19 \%$ of patients receiving DAC- $\beta 150 \mathrm{mg}(n=38 / 201)$, and $20 \%$ of patients receiving DAC- $\beta 300 \mathrm{mg}(n=40 / 203)$ experienced relapses while receiving treatment $(p<0.001$ and $p=0.00032$, respectively). Additionally, confirmed disability progression at 52 weeks was compared among the groups: $13 \%$ of patients on placebo $(n=25 / 196)$ had confirmed disability progression versus $6 \%$ of patients receiving DAC- $\beta 150 \mathrm{mg}(n=11 / 201)$ and $8 \%$ of patients receiving DAC- $\beta 300 \mathrm{mg}(n=15 / 203)$. Hazard ratios for disability progression were $0.43(95 \%$ CI $0.21-0.88 ; p=$ $0.021)$ and 0.57 (95\% CI $0.30-1.09 ; p=0.091)$ for the DAC- $\beta$ $150 \mathrm{mg}$ and $300 \mathrm{mg}$ groups, respectively, compared with placebo. There was also evidence of quality-of-life improvement as measured by the "Physical impact" score of the Multiple Sclerosis Impact Scale (MSIS)-29; the change from baseline was $3.0 \pm 13.5$ in the placebo group, $-1.0 \pm 11.8$ in the DAC- $\beta$ $150 \mathrm{mg}$ group, and $1.4 \pm 13.5$ in the DAC- $\beta 300 \mathrm{mg}$ group ( $p=$ 0.00082 and $p=0.13$, respectively, vs placebo). 
The SELECT study also had 2 associated extension studies: SELECTION and SELECTED [49, 50]. The SELECTION study (ClinicalTrials.gov, NCT00870740) [49] was a randomized, double-blind 1-year extension study in which patients who received placebo were assigned to receive either DAC- $\beta 150 \mathrm{mg}$ or $300 \mathrm{mg}$ subcutaneously every 4 weeks for 52 weeks ( $n=170$, treatment initiation group), and patients who received DAC- $\beta$ were randomized to either continue their present dose either with $(n=174$, washout and reinitiation group) or without ( $n=173$, continuous treatment group) a 20 -week washout period. This extension trial was also performed to evaluate for safety and immunogenicity, and results are discussed in the "Adverse Effects" section. Regarding clinical endpoints, the ARR for SELECTION was 0.165 (95\% CI 0.105-0.259) in the continuous treatment group, $0.179(95 \% \mathrm{CI} 0.123-0.261)$ in the treatment initiation group, and 0.302 (95\% CI 0.215-0.423) in the washout and re-initiation group. The ratio of the ARR for year 1 (placebo) and year 2 for the treatment initiation group was $0.466(95 \%$ CI $0.318-0.682 ; p<0.0001)$. Additionally, in the treatment initiation group, the number of patients with confirmed disability progression was statistically significantly reduced in year 2 compared with year 1 (odds ratio $0.414,95 \% \mathrm{CI}$ $0.182-0.944 ; p=0.033$ ). Based on these results, DAC- $\beta$ maintained its effectiveness and did not appear to be associated with increased incidence of immunogenicity or adverse events following year 2 of use. Importantly, a rebound effect was not observed following treatment discontinuation for washout purposes prior to re-initiation.

The SELECTED study (ClinicalTrials.gov, NCT01051349) [50] included $90 \%$ of the patients in SELECTION $(n=410)$, and involved all patients taking DAC- $\beta 150 \mathrm{mg}$ every 4 weeks for the third year of treatment and beyond (up to 6.5 years) in an open-label extension study. In terms of clinical efficacy, the adjusted ARR was examined at 6-month intervals from the first dose of DAC- $\beta$ and compared with the ARR from the placebo group of the year 1 SELECT trial. The adjusted ARR was 0.21 (95\% CI 0.16-0.29) for weeks 0 to 24 and 0.15 (95\% CI 0.10 0.21 ) for weeks 121 to 144 , demonstrating a reduction in the ARR in patients taking DAC- $\beta$ compared with those taking placebo.

The DECIDE study was a phase III, double-blind, multicenter, randomized controlled trial in which patients with RRMS ( $n=1841)$ were assigned to either DAC- $\beta 150 \mathrm{mg}$ subcutaneous injection every 4 weeks (with weekly intramuscular placebo) or intramuscular IFN- $\beta$ la (Avonex) $30 \mu \mathrm{g} \mathrm{ev-}$ ery week (with a subcutaneous placebo given every 4 weeks) for 96 to 144 weeks (ClinicalTrials.gov, NCT01064401) [51]. The primary endpoint for the DECIDE study was the ARR over a period of 144 weeks. Secondary clinical endpoints included the proportion of patients with confirmed disability progression over 144 weeks, the proportion of patients without relapses over 144 weeks, and the proportion of patients with a clinically meaningful improvement on the MSIS-29 physical subscale at 96 weeks.

Patients enrolled in the DECIDE trial $(n=1841)$ were primarily white $(90 \%)$, female $(68 \%)$, and $41 \%$ had previously been on disease-modifying therapy. The ARR was 0.39 in the IFN- $\beta 1$ a group and 0.22 in the DAC- $\beta$ group, a $45 \%$ relative risk reduction $(p<0.001)$. In terms of secondary endpoints, there was not a statistically significant difference between the IFN- $\beta 1 \mathrm{a}$ and DAC- $\beta$ groups in the percentage of patients with disability progression confirmed at 12 weeks $(20 \%$ vs $16 \% ; p=0.16)$, and, as a result, statistical testing was not conducted on further secondary endpoints. However, disability progression confirmed at 24 weeks was noted to be different between the groups; $18 \%$ of patients receiving IFN- $\beta 1 \mathrm{a}$ had confirmed disability progression at 24 weeks versus $13 \%$ of patients receiving DAC- $\beta(p=0.03)$. Additionally, the proportion of patients free from relapse at week 144 was $51 \%$ in the IFN- $\beta 1$ a group and $67 \%$ in the DAC- $\beta$ group (hazard ratio for relapse 0.59 , 95\% CI $0.50-0.69$; $p$-value not reported).

\section{Imaging Endpoints}

As discussed in the previous section, the primary endpoint of the CHOICE study was the number of new or enlarged gadolinium contrast-enhancing lesions on brain MRI performed every 4 weeks between weeks 8 and 24 of the study. An enlarged enhancing lesion was defined by an increase of at least $50 \%$ for lesions $<5 \mathrm{~mm}$ in diameter and an increase of $20 \%$ for lesions $>5 \mathrm{~mm}$ in diameter. Analyses were adjusted for baseline disease status and baseline lesion number. Patients in the IFN/placebo group had 4.75 new or enlarged contrast-enhancing lesions versus 1.32 in the IFN/high-dose DAC-SQ1 group (72\% difference, 95\% CI 34-88\%; $p=$ $0.004)$, and 3.58 in the IFN/low-dose DAC-SQ1 group (25\% difference, $95 \%$ CI 68 to $-76 ; p=0.51$ ). A sensitivity analysis was performed to evaluate the development of new contrastenhancing lesions, and it was found that the IFN/placebo group had 3.95 new lesions versus 1.18 in the IFN/highdose DAC-SQ1 group (70\% difference, 95\% CI 28-88\%; $p=0.01$ ), and 2.92 in the IFN/low-dose DAC-SQ1 group (26\% difference, $95 \% \mathrm{CI}-75$ to $69 ; p=0.49$ ).

Secondary imaging endpoints for the CHOICE study included the changes in number and volume of new or enlarged T2 and T1 lesions on brain MRI. This analysis was conducted at week 24, and demonstrated that the mean number of new or enlarged T2 lesions was 3.4 in the IFN/placebo group, 1.1 in the IFN/high-dose DAC-SQ1 group ( $p=0.007 v s$ IFN/placebo), and 2.2 in the IFN/low-dose DAC-SQ1 group ( $p=0.60 v s$ IFN/placebo). No differences were found in the change in T1 or T2 lesion volume change at week 24 in the low- and highdose DAC-SQ1 groups compared with the IFN/placebo group. 
Patients enrolled in the CHOICE study continued to have MRI scans performed at weeks 34 and 44, after the potential for treatment with DAC-SQ1 phase was complete but patients were continued on IFN therapy. The mean number of new contrast-enhancing lesions was calculated for these 2 MRI scans, and was compared among the groups adjusting for the number of contrast-enhancing lesions at baseline. No statistically significant differences were found: the patients receiving IFN/placebo had $2.3 \pm 0.81$ lesions versus $1.8 \pm 0.65$ in patients on IFN/high-dose DAC-SQ1 $(p=0.49$ compared with IFN/placebo) versus $3.5 \pm 1.18$ in patients on IFN/low-dose DAC-SQ1 ( $p=0.21$ compared with IFN/placebo).

The SELECT study also included several secondary imaging endpoints [48]. Overall, the number of new gadoliniumenhancing lesions at week 52 was higher in in patients receiving placebo $(1.4 \pm 2.3)$ than in those in the DAC- $\beta 150 \mathrm{mg}$ $(0.3 \pm 0.9)$ or $300 \mathrm{mg}(0.2 \pm 0.7)$ groups. Moreover, the odds ratio for contrast-enhancing lesion development was 0.15 (95\% CI $0.09-0.25$ ) for the DAC- $\beta 150 \mathrm{mg}$ group ( $p$ $<0.0001)$ and $0.12(95 \%$ CI $0.07-0.20)$ for the DAC $-\beta$ $300 \mathrm{mg}$ group $(p<0.0001)$ compared with placebo. There was a subset of patients on which more frequent MRI scans were performed every 4 weeks between 8 and 24 weeks, and the cumulative number of new gadolinium-enhancing lesions was compared among the treatment groups. Compared with placebo [ $n=104 ; 4.8$ lesions (95\% CI 3.6-6.4)], patients receiving DAC- $\beta 150 \mathrm{mg}(n=101)$ had 1.5 lesions $(95 \% \mathrm{CI}$ $1.1-2.0,69 \%$ reduction; $p<0.001)$ and those receiving $300 \mathrm{mg}(n=102)$ had an average of 1.0 lesions $(95 \% \mathrm{CI}$ $0.7-1.5,78 \%$ reduction; $p<0.0001)$. In terms of the number of new or enlarged T2 hyperintensities at week 52, patients receiving DAC- $\beta 150 \mathrm{mg}$ had 2.4 lesions (95\% CI 2.0-3.0) and those receiving $300 \mathrm{mg}$ had 1.7 (95\% CI 1.4-2.2) lesions versus the placebo group with 8.1 (95\% CI 6.7-9.9) lesions $(p<0.001$ for each comparison). The SELECTION and SELECTED extension studies $[49,50]$ demonstrated that this benefit associated with DAC- $\beta$ use was sustained in terms of gadolinium-enhancing T1 lesions and development of new or enlarging $\mathrm{T} 2$ hyperintensities.

In the DECIDE trial, DAC- $\beta 150 \mathrm{mg}$ subcutaneously every 4 weeks was compared with IFN- $\beta 1$ a $30 \mu \mathrm{g}$ intramuscularly every week [51]. Several secondary outcomes of this study were imaging-related. Patients receiving DAC- $\beta$ had a statistically significant decrease in the number of new or enlarged T2 hyperintensities on MRI over 96 weeks: patients in the IFN- $\beta 1$ a group had a mean of 9.4 (95\% CI 8.5-10.5) lesions, whereas patients in the DAC- $\beta$ group had a mean of 4.3 (95\% CI 3.9-4.8), representing a $54 \%$ reduction $(95 \%$ CI $47-61 \%)$ of lesions in the DAC- $\beta$ group $(p<0.001)$. There was also a statistically significant reduction in the mean number of gadolinium-enhancing lesions in the DAC- $\beta$ group $(0.4 \pm 1.4)$ compared with the IFN- $\beta 1$ a group $(1.0 \pm 2.8)$, with an odds ratio of 0.25 (95\% CI $0.20-0.32 ; p<0.001)$.
Similarly, there was a statistically significant reduction in the adjusted mean number of new T1 hypointensities over 96 weeks in the DAC- $\beta$ group $(2.13,95 \%$ CI $1.94-2.35)$ compared with IFN- $\beta 1$ a $(4.43,95 \%$ CI $4.05-4.84)$, with a percentage reduction of $52 \%$ (95\% CI $45-58 \% ; p<0.001$ ).

\section{Adverse Effects}

\section{Serious Adverse Effects}

Throughout clinical trials, Daclizumab has been relatively well tolerated, but some safety concerns have arisen over time. The most serious adverse effects that can be associated with daclizumab treatment include liver function testing abnormalities, cutaneous reactions, infections, and autoimmune phenomena. Each of these categories is discussed in detail below, including the incidence of each adverse effect versus comparators in clinical trials (Table 4). It is also important to consider the formulation and administration route of daclizumab when discussing adverse events, as earlier studies used intravenous daclizumab (DAC-IV; Zenapax ${ }^{\mathrm{TM}}$ ), and others used daclizumab subcutaneous injections [DAC-SQ1 (CHOICE) or DAC- $\beta$ (previously referred to as DAC-HYP; SELECT and DECIDE studies)].

A recent article published by Giovannoni et al. [52] provides a pooled analysis of adverse events from the SELECT, DECIDE, OBSERVE, SELECTION, SELECTED, and EXTEND studies, which encompassed 2236 patients with 5214 patient-years of daclizumab exposure (maximum of 6.5 years) [52]. Adverse events in the setting of daclizumab use were stratified by the dose received, either $150 \mathrm{mg}(n=$ $1943)$ or $300 \mathrm{mg}(n=293)$. It is important to note that comparator data was not included owing to heterogeneity across studies. Overall, 16\% $(n=354)$ of patients receiving daclizumab experienced a severe adverse effect other than MS relapse. Most adverse events were either of mild ( $n=$ $546 ; 24 \%)$ or moderate $(n=1080 ; 48 \%)$ severity, and $13 \%$ of patients $(n=299)$ receiving daclizumab had to discontinue treatment owing to an adverse event other than MS relapse. Results from each individual study will be discussed below.

\section{Liver Enzyme Testing Abnormalities}

Elevations in liver enzymes have been reported with daclizumab in clinical trials, as have cases of autoimmune hepatitis. In the CHOICE study, the percentage of patients experiencing toxic hepatitis (degree of elevation in liver enzymes not delineated) was $0 \%$ in the IFN/placebo group, $0 \%$ in the IFN/low-dose DAC-SQ1 group, and $1.3 \%$ in the IFN/ high-dose DAC-SQ1 group [47]. However, it was noted that 4 patients receiving DAC-SQ1 discontinued treatment owing to 
Table 4 Side effects of daclizumab (DAC) versus comparator across pivotal clinical trials

\begin{tabular}{|c|c|c|c|c|c|c|c|c|c|}
\hline \multirow[b]{2}{*}{$\mathrm{AE}$} & \multicolumn{4}{|c|}{ CHOICE $(n=230)$} & \multicolumn{3}{|c|}{ SELECT $(n=621)$} & \multicolumn{2}{|c|}{ DECIDE $(n=1841)$} \\
\hline & $\begin{array}{l}\text { Placebo } \\
\quad \text { and IFN } \\
-\beta 1 \\
(n=77)\end{array}$ & $\begin{array}{l}\text { Low-dose } \\
\text { DAC-SQ1 and } \\
\text { IFN - } \beta 1 \\
(n=78)\end{array}$ & $\begin{array}{l}\text { High-dose } \\
\text { DAC-SQ1 and } \\
\text { IFN - } \beta 1 \\
(n=75)\end{array}$ & $\begin{array}{l}\text { DAC (SQ1) } \\
\text { groups } \\
\text { total } \\
(n=153)\end{array}$ & $\begin{array}{l}\text { Placebo } \\
(n=204)\end{array}$ & $\begin{array}{c}\text { DAC- } \beta \\
150- \\
\mathrm{mg} \\
(n=208)\end{array}$ & $\begin{array}{c}\text { DAC- } \beta \\
300- \\
\text { mg } \\
(n=209)\end{array}$ & $\begin{array}{l}\text { IFN }-\beta 1 \mathrm{a} \\
(n=922)\end{array}$ & $\begin{array}{c}\text { DAC }-\beta \\
150- \\
\mathrm{mg} \\
(n=919)\end{array}$ \\
\hline Any AE & $75(97)$ & $78(100)$ & $71(95)$ & $149(97)$ & $161(79)$ & $151(73)$ & $159(76)$ & $842(91)$ & $838(91)$ \\
\hline Any SAE & $13(17)$ & $18(21)$ & $20(27)$ & $38(25)$ & $53(26)$ & $32(15)$ & $36(17)$ & $194(21)$ & $221(24)$ \\
\hline $\begin{array}{l}\text { Any SAE, excluding MS } \\
\text { relapse }\end{array}$ & NA & NA & NA & NA & $12(6)$ & $15(7)$ & $19(9)$ & $88(10)$ & $142(15)$ \\
\hline $\begin{array}{l}\text { Elevated LFTs/toxic hep- } \\
\text { atitis }\end{array}$ & NA & NA & $1(1)$ & $1(2)$ & $71(35)$ & $70(34)$ & $76(36)$ & NA & NA \\
\hline $1-3 \times \mathrm{ULN}$ & NA & NA & NA & NA & $64(31)$ & $54(26)$ & $62(30)$ & NA & NA \\
\hline $3-5 \times$ ULN & NA & NA & NA & NA & $6(3)$ & $7(3)$ & $6(3)$ & NA & NA \\
\hline$>3 \times \mathrm{ULN}$ & NA & NA & NA & NA & NA & NA & NA & $80(9)$ & $96(10)$ \\
\hline$>5 \times \mathrm{ULN}$ & NA & NA & NA & NA & $1(<1)$ & $9(4)$ & $8(4)$ & $31(3)$ & $59(6)$ \\
\hline $\begin{array}{l}\text { AST/ALT }>3 \times \text { ULN and } \\
\text { total bilirubin }>2 \times \\
\text { ULN }\end{array}$ & NA & NA & NA & NA & NA & NA & NA & $1(<1)$ & $7(1)$ \\
\hline Cutaneous reactions & NA & NA & NA & NA & $27(13)$ & $38(18)$ & $45(22)$ & $176(19)$ & $344(37)$ \\
\hline Rash & $6(8)$ & $14(18)$ & $6(8)$ & $20(13)$ & $6(3)$ & $12(6)$ & $11(5)$ & $26(3)$ & $64(7)$ \\
\hline Eczema & $0(0)$ & $1(1)$ & $1(1)$ & $2(1)$ & NA & NA & NA & $13(1)$ & $40(4)$ \\
\hline Serious cutaneous events & NA & NA & NA & NA & $0(0)$ & $2(<1)$ & $3(<1)$ & $1(<1)$ & $14(2)$ \\
\hline Infections & $52(68)$ & $54(69)$ & $51(68)$ & $105(69)$ & $89(44)$ & $104(50)$ & $112(54)$ & $523(57)$ & $595(65)$ \\
\hline UTI & $12(16)$ & $13(17)$ & $17(23)$ & $30(20)$ & NA & NA & NA & $98(11)$ & $96(10)$ \\
\hline URI & $12(16)$ & $12(15)$ & $17(23)$ & $29(19)$ & $14(7)$ & $18(9)$ & $22(11)$ & $124(13)$ & 149 (16) \\
\hline Nasopharyngitis & $14(18)$ & $17(22)$ & $10(13)$ & $27(18)$ & $31(15)$ & $30(14)$ & $30(14)$ & $197(21)$ & $226(25)$ \\
\hline Pneumonia & $1(1)$ & $1(1)$ & $0(0)$ & $1(1)$ & & & & $2(<1)$ & $5(1)$ \\
\hline Serious infection & & & & & $0(0)$ & $6(3)$ & $3(1)$ & $15(2)$ & $40(4)$ \\
\hline Lymphopenia & $1(1)$ & $1(1)$ & $0(0)$ & $1(1)$ & NA & NA & NA & $\begin{array}{l}18(2) \\
(\mathrm{ALC}< \\
500)\end{array}$ & $7(1)$ \\
\hline $\begin{array}{l}\text { Thrombocytopenia } \\
\text { (platelets < 100) }\end{array}$ & & & & & & & & $9(1)$ & $10(1)$ \\
\hline Malignancies & $0(0)$ & $1(1)$ & $1(1)$ & $2(1)$ & $1(<1)$ & $1(<1)$ & $2(<1)$ & $8(1)$ & $7(1 \%)$ \\
\hline Breast cancer (DCIS) & $0(0)$ & $1(1)$ & $0(0)$ & $1(1)$ & NA & NA & NA & NA & NA \\
\hline Pseudomyxoma peritonei & $0(0)$ & $0(0)$ & $1(1)$ & $1(1)$ & NA & NA & NA & NA & NA \\
\hline Cervical carcinoma & NA & NA & NA & NA & $1(<1)$ & $1(<1)$ & NA & NA & NA \\
\hline Melanoma & NA & NA & NA & NA & NA & NA & $2(<1)$ & NA & NA \\
\hline $\begin{array}{l}\text { Injection site } \\
\text { reaction/pain }\end{array}$ & NA & NA & NA & NA & $3(1)$ & $4(2)$ & $4(2)$ & $102(11)$ & $96(10)$ \\
\hline Irritation & $18(23)$ & $14(18)$ & $14(19)$ & $28(18)$ & NA & NA & NA & NA & NA \\
\hline Pain & $19(25)$ & $13(17)$ & $9(12)$ & $22(14)$ & NA & NA & NA & NA & NA \\
\hline Lymphadenopathy & NA & NA & NA & NA & $0(0)$ & $0(0)$ & $1(<1)$ & $0(0)$ & $5(1)$ \\
\hline Lymphadenitis & NA & NA & NA & NA & NA & NA & NA & $0(0)$ & $3(<1)$ \\
\hline
\end{tabular}

Data are $n(\%) . \mathrm{AE}=$ adverse event; $\mathrm{IFN}=$ interferon; $\mathrm{SAE}=$ serious $\mathrm{AE} ; \mathrm{MS}=$ multiple sclerosis; $\mathrm{NA}=$ not applicable; $\mathrm{LFT}=$ liver function test; $\mathrm{ULN}=$ upper limit of normal; AST = aspartate aminotransferase; ALT = alanine aminotransferase; UTI = urinary tract infection; URI = upper respiratory infection; DCIS $=$ ??; ALC $=$ ??

elevated liver enzymes, in addition to headache, pyrexia, and rash.

In the SELECT trial, a similar percentage of patients in each group developed liver enzyme elevations of 1 to 3 and 3 to 5 times the upper limit of normal (ULN) (Table 4) [48].
However, patients receiving DAC- $\beta 150 \mathrm{mg}$ or $300 \mathrm{mg}$ were more likely to have liver enzyme elevations of $>5$ times the ULN than with placebo ( $4 \%$ of patients on DAC- $\beta 150 \mathrm{mg}$, $4 \%$ of patients on DAC- $\beta 300 \mathrm{mg} v s<1 \%$ of patients on placebo). It was noted that the observed increases in liver 
enzymes occurred later in the treatment period (median onset at day 308) and resolved in a median time of 62 days (range 39.5-98 days). Additionally, it is important to note that 2 patients in the DAC- $\beta 150 \mathrm{mg}$ group had liver enzyme elevations associated with hepatitis $\mathrm{B}$ and cytomegalovirus infections. In terms of treatment continuation, 7 of the 17 patients in whom liver enzymes were $>5$ times the ULN were able to continue or resume treatment after resolution of this elevation; importantly, none of these patients who resumed treatment with DAC- $\beta$ had recurrence of liver enzyme elevation in the following 5 months.

The SELECTION and SELECTED trial, as mentioned previously, were extension studies of the SELECT trial. In the SELECTION study, there were similar percentages of patients developing liver enzyme elevation $>5$ times the ULN across all treatment groups (both DAC- $\beta 150 \mathrm{mg}$ and $300 \mathrm{mg}$ ) over a 1 -year extension. However, the proportion of patients receiving DAC- $\beta 150 \mathrm{mg}$ (all groups) who had $>5$ times the ULN was $1.2 \%(n=3 / 258)$ versus $3.1 \%(n=8 / 259)$ of patients receiving DAC- $\beta 300 \mathrm{mg}$. Ten of these 11 patients who had liver enzyme elevation $>5$ times the ULN were able to resume DAC- $\beta$ treatment without recurrence. However, 1 patient in the washout/re-initiation of DAC- $\beta 300 \mathrm{mg}$ group did not resume treatment owing to development of autoimmune hepatitis that unfortunately led to death. In the SELECTED study, all patients were receiving DAC- $\beta 150 \mathrm{mg}(n=410)$; the occurrence of liver enzyme elevations $\geq 3$ times the ULN was $9 \%,>5$ times the ULN was $4 \%$, and $>10$ times the ULN was $3 \%$. Two patients in the SELECTED study had liver enzyme elevation $>3$ times the ULN with elevation of bilirubin levels $>2$ times the ULN while on DAC- $\beta$. One case of liver enzyme elevation that occurred after discontinuation of treatment was felt to be related to valproic acid use, and the other case occurred 8 weeks after treatment discontinuation in the setting of herbal supplements and use of an acetaminophencontaining medication [50].

The DECIDE study, which compared subcutaneous DAC- $\beta 150$ mg with IFN- $\beta 1$ a, reported elevation of aspartate aminotransferase (AST) or alanine aminotransferase (ALT) > 5 times the ULN in $6 \%$ of patients on DAC- $\beta$ versus $3 \%$ of patients on IFN- $\beta 1 \mathrm{a}$ [51]. Additionally, elevations in liver enzymes occurred in the first year of IFN treatment, compared with occurring equally over the timespan during which patients were treated with DAC- $\beta$. One patient in each treatment group had AST/ALT $>3$ times the ULN, along with a total bilirubin of $>2$ times the ULN.

\section{Cutaneous Reactions}

Reported cutaneous reactions in the setting of daclizumab include rash, eczema, allergic dermatitis, erythema, drug eruption, erythema nodosum, psoriasis, toxic skin eruption, urticaria, exfoliative dermatitis, recurrent granuloma annulare, and erhythema multiforme [53-55]. There were also reported cases of DRESS and Stevens-Johnson syndrome in the DECIDE and SELECTED trials, respectively, but after adjudication by a central dermatologist these were considered to be delayed drug hypersensitivity rashes [52]. Generally, most cutaneous reactions are mild, can be treated with topical steroids, and do not preclude use of daclizumab [55]. Regarding etiology of the cutaneous reactions seen with daclizumab, it is felt that given the presence of $\mathrm{CD}^{2} 6^{+}$lymphocytic infiltrates on biopsies, these cutaneous reactions are related to the immunomodulatory effects of daclizumab particularly on NK cells [53].

In the CHOICE study, rash was a somewhat common side effect among participants. In the IFN/placebo group $8 \%$ reported rash versus $18 \%$ in the IFN/low-dose DAC-SQ1 and $8 \%$ in the IFN/high-dose DAC-SQ1 groups (13.3\% of DACSQ1 patients overall) [47]. As mentioned above, it was noted that 4 patients receiving DAC-SQ1 discontinued treatment owing to rash, in addition to headache, pyrexia, and elevated liver enzymes.

The SELECT trial found that more patients had cutaneous events in the daclizumab groups than the placebo group. Serious cutaneous events occurred in 2 patients in the DAC- $\beta 150 \mathrm{mg}$ group and 3 in the $300 \mathrm{mg}$ group versus none in the placebo group [48]. These serious cutaneous events consisted of erythema nodosum, atopic dermatitis, exfoliative dermatitis, rash, and allergic dermatitis. One patient who developed a serious rash on DAC- $\beta$ died as a result of thrombotic complications of a psoas abscess resulting in acute ischemic colitis. In the SELECTION trial, 6 patients $(1 \%)$ developed serious cutaneous events: drug eruption and eczema in the DAC- $\beta 150 \mathrm{mg}$ treatment initiation group, pityriasis rubra piliaris in the $150 \mathrm{mg}$ washout/re-initiation group, and exfoliative dermatitis, urticaria, and drug eruption with ecze$\mathrm{ma}$ in the DAC- $\beta 300 \mathrm{mg}$ continuous treatment group [49]. In the SELECTED trial, $2 \%$ of patients taking DAC $-\beta(n=8)$ reported serious cutaneous events, including urticaria $(n=2)$, allergic dermatitis, erythrodermic psoriasis, Stevens-Johnson syndrome (but dermatologic consultation did not confirm this diagnosis), and toxic skin eruption. Twenty-eight percent of patients reported cutaneous events, most of which were considered mild. Cutaneous side effects resulted in discontinuation of DAC- $\beta$ in $3 \%$ of patients.

The DECIDE trial reported the occurrence of cutaneous events as $37 \%$ of patients receiving DAC- $\beta$ compared with $19 \%$ of patients receiving IFN- $\beta$ 1a [51]. Cutaneous events led to treatment discontinuation in $5 \%$ of patients taking DAC- $\beta$ and $1 \%$ of patients receiving IFN- $\beta 1 \mathrm{a}[51$, 55]. The most common of these events were rash $(7 \%)$ and eczema (4\%) (Table 4). Serious cutaneous events occurred in $2 \%$ of the DAC- $\beta$ group versus $<1 \%$ of the IFN- $\beta 1$ a group, and included dermatitis and angioedema [51]. 
Krueger et al. [55] published an additional work examining the cutaneous adverse events seen in the DECIDE study, as well as their subsequent management [55]. It was noted that cutaneous adverse events accounted for 30\% (43/142) and 6\% $(7 / 112)$ of treatment discontinuations in the DAC- $\beta$ and IFN- $\beta$ 1a groups, respectively. However, most patients who experienced cutaneous events were able to remain on treatment ( $81 \%$ in DAC- $\beta$ and $90 \%$ of IFN- $\beta$ 1a patients). Additionally, most patients with mild or moderate cutaneous adverse events did not require corticosteroid treatment or were treated with topical corticosteroids only. However, most patients with severe cutaneous adverse events (17/21 of DAC- $\beta$ and $1 / 3$ of IFN- $\beta 1$ a patients) received systemic corticosteroids.

\section{Serious Infections}

In the CHOICE study, infections were the most common grade 3 adverse event, occurring in $3 \%(n=2)$ of the IFN/ placebo group and 7\% $(n=10)$ in the IFN/DAC-SQ1 groups combined [47]. The risk of serious infections was increased in patients on DAC-SQ1 (5\%) compared with IFN/placebo $(1 \%)$. However, there were no reports of opportunistic infections or deaths in this study. Overall, the SELECT study reported that $2 \%$ of patients on DAC- $\beta(n=9 / 153)$ had serious infections versus $0 \%$ of patients receiving placebo [48]. Of patients who had a serious infection while receiving study treatment $(n=7), 1$ discontinued treatment owing to the infection, but 6 were able to resume treatment after resolution of the infection. Oral herpes virus infections were similar across treatment groups: $5 \%(n=10)$ in the placebo group, $5 \%(n=$ $10)$ in the DAC- $\beta 150 \mathrm{mg}$ group, and $6 \%(n=13)$ in the DAC- $\beta 300 \mathrm{mg}$ group, but one patient in each group did develop herpes zoster.

In the SELECTION trial, bronchitis was the only serious infection reported in $>1$ patient $(n=3,1$ each in DAC- $\beta$ $300 \mathrm{mg}$ washout/re-initiation, $150 \mathrm{mg}$ washout/re-initiation, and $150 \mathrm{mg}$ initiation groups). Otherwise, $2.5 \%$ of patients $(n=13 / 517)$ in the study developed a serious infection. The SELECTED trial $(n=410)$ reported that $3 \%$ of patients on DAC- $\beta$ developed serious infections [pneumonia $(n=3)$, urinary tract infection (UTI; $n=3)$, bronchitis $(n=2)$, Clostridium difficile colitis $(n=1)$, infectious mononucleosis $(n=1)$, hepatitis $\mathrm{C}(n=1)$, and diverticulitis $(n=1)]$, without evidence of an increase in infection risk over time. Additionally, 1 patient living in an endemic area developed pulmonary tuberculosis [50].

The DECIDE trial reported serious infection in $4 \%$ of patients receiving DAC- $\beta$ versus $2 \%$ of those receiving IFN- $\beta 1$ a [51]. Such infections included UTI, pneumonia, appendicitis, cellulitis, and viral infection. No cases of infectious encephalitis or progressive multifocal leukoencephalopathy (PML) were reported during the study.

\section{Autoimmune Phenomena}

The CHOICE study did not note specific autoimmune phenomena occurring in patients taking DAC-SQ1 [47]. However, the SELECT trial noted potential immunemediated serious adverse events in patients on DAC- $\beta$ $300 \mathrm{mg}$ (each $n=1$ ): autoimmune thyroiditis, Crohn's disease, hypersensitivity, and lymphadenopathy [48]. In the SELECTION trial, there was a case of autoimmune hepatitis in a patient receiving DAC- $\beta$ that resulted in death [49]. Additionally, the SELECTION study reported 1 case each of Graves' disease (hyperthyroidism) and glomerulonephritis, as well as 2 cases of ulcerative colitis in the continuous treatment $300 \mathrm{mg}$ DAC- $\beta$ group. The SELECTED trial reported 3 cases of ulcerative colitis, 1 case of Crohn's disease, and 1 case of autoimmune hepatitis, all of which occurred in patients receiving DAC $-\beta 150 \mathrm{mg}$. In the largest study of DAC- $\beta$, the DECIDE study, there was no specific identification of cases of autoimmune phenomena. However, the US Prescribing Information for DAC- $\beta$ indicates a $32 \%$ incidence of "immune-mediated disorders" in patients receiving DAC- $\beta$ versus $12 \%$ of patients receiving IFN- $\beta 1$ a. It is unclear which conditions were included in this seemingly broad category, as this statistic is not discussed in the DECIDE paper or elaborated upon in the US Prescribing Information [51, 56].

In Giovannoni et al.'s [52] integrated analysis of adverse events associated with daclizumab use, it was reported that the cumulative incidence of potential autoimmune disorders was $1.4 \%$, and of potential serious autoimmune adverse events was $0.4 \%$ across clinical trials [52]. It was noted that autoimmune thyroiditis was the most common autoimmune condition overall, as it occurred in 6 patients across clinical trials and with a cumulative incidence of $0.3 \%$. Of 10 serious adverse autoimmune events, 3 were autoimmune hepatitis, 1 of which resulted in liver failure and death. Other serious autoimmune disorders included autoimmune thyroiditis, Graves' disease, celiac disease, lupus-like syndrome, myasthenia gravis, pernicious anemia, and Reiter's syndrome that were each reported in 1 patient across clinical trials. Again, it is important to note that this analysis did not take comparator data into account.

\section{Malignancies}

The risk of malignancy is an important consideration with use of immunomodulatory or immunosuppressive medications, particularly in the long term. In the CHOICE study, 2 patients taking DAC-SQ1 developed malignancy. One developed breast cancer (ductal carcinoma in situ) $>1$ year after the patient's last dose of DAC-SQ1, and 1 patient had recurrence of pseudomyxoma peritonei [47]. The SELECT trial noted development of 4 malignancies: 2 cervical carcinoma cases ( 1 in placebo group and 1 in the DAC- $\beta 150 \mathrm{mg}$ group) and 2 
melanoma cases (both in the DAC- $\beta 300 \mathrm{mg}$ group). In the SELECTION study, there was 1 patient in the treatment initiation group receiving DAC- $\beta 300 \mathrm{mg}$ group who developed breast cancer [49]. The SELECTED study noted 1 case each of breast cancer, basal cell carcinoma, anal cancer, and pulmonary carcinoid tumor in patients receiving DAC- $\beta$. The phase III DECIDE study reported 8 cases of malignancy in the IFN- $\beta 1$ a group (endometrial cancer, malignant melanoma, metastatic pancreatic carcinoma, squamous cell carcinoma, cervical squamous cell carcinoma, oral squamous cell carcinoma, testicular seminoma, and a malignant tongue neoplasm) and 7 cases of malignancy in the DAC- $\beta$ group (basal cell carcinoma, malignant brain neoplasm, invasive ductal breast carcinoma, squamous cell carcinoma of the lip, thyroid cancer, transitional cell carcinoma, and uterine cancer) (Table 4) [51]. Although these results do not indicate increased risk of malignancy associated with daclizumab use in the short term, the risk of malignancy associated with long-term use cannot be excluded.

\section{Common Adverse Events}

\section{Infections}

In the CHOICE study, $16 \%$ of patients in the IFN/placebo group developed upper respiratory tract infection versus $15 \%$ and $23 \%$ in the low- and high-dose DAC-SQ1 groups, respectively [47]. Additionally, $18 \%$ of patients in the IFN/ placebo group developed upper respiratory tract infection versus $22 \%$ and $13 \%$ in the low- and high-dose DAC-SQ1 groups, respectively [47]. The SELECT trial noted a similar incidence of upper respiratory tract infection (7\% in placebo vs $9 \%$ and $11 \%$ in DAC- $\beta 150 \mathrm{mg}$ and $300 \mathrm{mg}$ groups, respectively) and nasopharyngitis (15\% in placebo vs $14 \%$ in both DAC- $\beta$ groups) across study groups [48]. The occurrence of nasopharyngitis (12.8\% in DAC- $\beta 150 \mathrm{mg}$ and $12.7 \%$ in DAC- $\beta 300 \mathrm{mg}$ groups) and upper respiratory infection (8.6\% in DAC- $\beta 150 \mathrm{mg}$ and 6.6\% in DAC- $\beta 300 \mathrm{mg}$ groups) remained stable throughout the SELECTION study as well. In the DECIDE study, $13 \%(n=124 / 922)$ of patients receiving IFN- $\beta 1 \mathrm{a}$ and $16 \%(n=149 / 919)$ of patients receiving DAC- $\beta 150 \mathrm{mg}$ developed upper respiratory tract infection; $21 \%(n=197 / 922)$ of patients receiving IFN- $\beta 1 \mathrm{a}$ and $25 \%(n=226 / 919)$ receiving DAC- $\beta 150 \mathrm{mg}$ developed nasopharyngitis. Although statistical testing for differences in incidence of these infections is not reported across the previously mentioned clinical trials, it appears that daclizumab is associated with a slightly elevated risk of upper respiratory tract infections and nasopharyngitis; however, this observed increase is not unexpected given the presumed increased risk of infection overall associated with immunosuppressive therapy (Table 4).
Regarding UTIs, it was reported in the CHOICE study that $16 \%$ of patients in the IFN/placebo group developed UTI versus $17 \%$ and $23 \%$ in the low- and high-dose DAC-SQ1 groups, respectively [47]. The SELECT/SELECTION studies did not report specifically on the occurrence of UTI. However, the SELECTED study $(n=410)$ noted development of UTI in 3 patients taking DAC $-\beta(<1 \%)$ [50]. In the DECIDE trial, $11 \%(n=98 / 922)$ of patients receiving IFN- $\beta 1 \mathrm{a}$ and $10 \%(n=$ 96/919) of patients receiving DAC- $\beta$ developed UTI. Overall, there does not appear to be a substantially elevated risk of UTI in patients receiving daclizumab versus IFN- $\beta 1$ a.

\section{Injection Site Reactions or Pain}

The CHOICE study reported that injection site reactions were more common in the IFN/placebo group $(44 \% ; n=34 / 77)$ than in the IFN/low-dose DAC-SQ1 $(38 \% ; n=30 / 78)$ and IFN/high-dose DAC-SQ1 (35\%; $n=26 / 75)$ [47]. In the SELECTION trial, $2.7 \%$ of patients receiving DAC- $\beta(1.9 \%$ in $150 \mathrm{mg}$ group and $3.5 \%$ in $300 \mathrm{mg}$ group) had injection-site related adverse events, but none was considered serious or resulted in treatment discontinuation [49]. The DECIDE study reported that $11 \%$ of patients $(n=102 / 922)$ receiving IFN- $\beta 1$ a experienced injection site pain versus $10 \%$ of patients $(n=96 /$ 919) receiving DAC- $\beta$.

\section{Gastrointestinal Side Effects}

In terms of gastrointestinal (GI) side effects, there have been concerns regarding potential inflammatory GI side effects associated with daclizumab. Per Giovannoni et al. [52], the cumulative incidence of inflammatory GI adverse events in patients across clinical trials is $1 \%(n=26 / 2236)$, with a higher incidence noted in patients receiving daclizumab $300 \mathrm{mg}(2 \%$ $v s<1 \%$ in $150 \mathrm{mg}$ dose) [52]. Reported serious adverse events include ulcerative colitis $(n=6 / 2236)$, colitis $(n=2 /$ 2236), Crohn's disease $(n=2 / 2236)$, ischemic colitis $(n=1 /$ 2236), microscopic colitis ( $n=1 / 2236)$, and hemorrhagic enterocolitis $(n=1 / 2236)$. However, the reported cumulative incidence of any GI adverse event was reported to be $25 \%$, with any serious GI adverse event reported as $2 \%$ [52]. Additionally, nausea and vomiting have been reported in $3 \%$ of the clinical trial population receiving daclizumab. Diarrhea has been reported in 7\%, and constipation in 3\% [52].

In the SELECTED trial, 6 patients (1\%) reported serious inflammatory gastrointestinal events while on DAC- $\beta$, including ulcerative colitis, colitis, Crohn's disease, and hemorrhagic enterocolitis. These patients discontinued treatment and were treated accordingly, with the majority stabilizing without flares after discontinuation of study treatment and/or appropriate colitis standard of care [50]. 


\section{Other Laboratory Abnormalities}

Other than elevated hepatic enzymes, no significant laboratory derangements associated with daclizumab were reported in the CHOICE, SELECT, or DECIDE studies [47, 48, 51]. There were some reported cases of lymphopenia $\left(<0.8 \times 10^{9}\right.$ cells/l) and leukopenia $\left(<3.0 \times 10^{9}\right.$ cells/l) across the clinical trials, but the overall incidence remains low ( $7 \%$ and $4 \%$, respectively) [52].

\section{Summary of Adverse Events}

Overall, patients receiving DAC-SQ1 (CHOICE) or DAC- $\beta$ (SELECT and DECIDE) had a similar risk of any adverse event as the placebo or active comparator groups in each clinical trial. However, there did appear to be a slightly increased risk (1-10\%) of any serious adverse event in patients receiving daclizumab versus comparator groups (placebo or IFN). Adverse events are summarized across each clinical trial in Table 4.

Cutaneous events are a concern with use of daclizumab, and it was reported that across clinical trials, the incidence of any cutaneous adverse event was $33 \%$ in patients receiving daclizumab [52]. Additionally, 1 study of 31 patients enrolled in a phase I study of daclizumab (both intravenous and subcutaneous formulations) reported this incidence to be as high as $77 \%$, with the majority of cases being related to eczema [53]. Serious cutaneous events did occur in $<1 \%$ to $2 \%$ of patients receiving daclizumab versus $0 \%$ with placebo or $<$ $1 \%$ with IFN- $\beta 1$ a across clinical trials; Giovannoni et al.'s [52] integrated analysis reported this incidence as $2 \%$ across clinical trials (Table 4) [52]. In the DECIDE study experience, although cutaneous adverse events were more common with DAC- $\beta$, the majority were mild or moderate, did not require systemic corticosteroid treatment, and did not necessitate discontinuation of daclizumab [55]. The nature of these adverse events is discussed previously, but is felt to be related to the immunomodulatory effects of daclizumab on lymphoid cells, including NK cells [53].

Regarding elevations in liver function testing, the overall incidence of elevation was similar across treatment groups, but patients receiving daclizumab had higher degrees of AST/ALT elevation. There was a slight increase in upper respiratory tract infections ( $2-4 \%$ vs comparator) with DAC- $\beta$ use in the SELECT and DECIDE studies. Additionally, there were increased incidence of nasopharyngitis (4-5\% vs comparator) in the CHOICE and DECIDE studies, but this difference was not observed in the SELECT trial. There does not appear to be a significantly increased risk of malignancy or lymphopenia with daclizumab compared with placebo or IFN- $\beta 1$ a. However, the short-term nature of these studies does not exclude a risk of malignancy with long-term daclizumab use.

\section{Use of Daclizumab in Clinical Practice}

\section{Considerations for Use of Daclizumab}

Daclizumab- $\beta$ (DAC- $\beta$; Zinbryta ${ }^{\mathrm{TM}}$ ) was approved for relapsing forms of MS by the FDA in August 2016. Contraindications to DAC- $\beta$ include pre-existing hepatic disease or impairment, with AST/ALT $>2$ times the ULN, a history of autoimmune hepatitis or other autoimmune liver disease, or hypersensitivity to DAC- $\beta$ or its components. Depression-related events have been reported in clinical trials of DAC- $\beta$, so caution is advised with use of DAC- $\beta$ in patients with comorbid depression. Additionally, despite prior studies of intravenous daclizumab in pediatric patients [57], use of DAC- $\beta$ is not recommended in pediatric patients $<$ 18 years of age [56]. It is felt that data are insufficient to recommend use in elderly populations $>65$ years of age. DAC- $\beta$ use is not recommended in women who are pregnant, planning to become pregnant, or breastfeeding.

A provider should consider use of DAC- $\beta$ in patients with generally active RRMS who have not responded $\geq 2$ disease modifying therapies.

The United States (US) Risk Evaluation and Mitigation Strategy (REMS) program for daclizumab use requires that a patient should have previously been treated with 2 immune therapies as well. Based on a conservative clinical approach in which immunomodulatory therapies, particularly glatiramer acetate and IFN- $\beta$, are initially utilized, this is a reasonable approach. Additionally, data from active comparator trials on new agents is suggestive of a cluster of therapies, namely DAC- $\beta$, fingolimod, and ocrelizumab with very similar degrees of effectiveness as IFN- $\beta 1 \mathrm{a}$ in phase III trials [ARR reduction of $45 \%$ (DECIDE), 52\% (TRANSFORMS), and $46 \%$ (OPERA I), respectively] [51, 58, 59]. Daclizumab is a valuable addition as an option for disease-modifying therapy of moderate-to-high effectiveness in RRMS.

Other considerations for use of DAC- $\beta$ include its route of administration. As DAC- $\beta$ is administered via subcutaneous injection, it can be convenient for patients with poor intravenous access or those who may have difficulty with access to infusion centers. Additionally, the absence of PML cases in clinical trials make DAC- $\beta$ a potential treatment for patients who are JC virus-positive; however, longer-term use of DAC- $\beta$ is required to adequately assess the risk of PML.

Recent analysis of data from the DECIDE trial reveals reduction of disability with DAC- $\beta$ relative to IFN- $\beta 1$ a on 3 measures: 1) modified Multiple Sclerosis Functional Composite-3, 2) EDSS, and 3) MSIS-29 "Physical score" [60]. The effects of DAC- $\beta$ were independent of sex, age, disease duration, prior MS therapy, and baseline EDSS; however, the most pronounced benefits in terms of disability were observed in patients under the age of 35 years and with an EDSS $<3.5$. 
SELECT and DECIDE trial results for patient subgroups, including sex, age, relapses in the year prior to study, disease duration, baseline disability, presence of gadoliniumenhancing lesions, and T2 hyperintensity lesion volume indicated that diverse clinically important subgroups respond to DAC- $\beta$ [61]. Similar to the DECIDE subgroup analyses discussed above, this analysis indicated that younger patients with shorter disease duration $(<10$ years) may have increased benefit with DAC- $\beta$ use. These studies suggest that a wide range of patients with RRMS may be effectively treated with DAC- $\beta$ in the context of the REMS program. Emerging data from extension trials will also help to identify the most sensitive populations in terms of response to therapy, as well as the longer-term risks and benefits of DAC- $\beta$.

\section{Practical Aspects of Daclizumab Use}

\section{Administration}

DAC- $\beta$ (Zinbryta $\left.{ }^{\mathrm{TM}}\right)$ is a once-monthly, self-administered subcutaneous injection that is provided to patients in a single-use, prefilled syringe. Potential injection sites include the thigh, abdomen, or posterior aspect of the upper arm. DAC- $\beta$ requires refrigeration, but should be removed from the refrigerator $30 \mathrm{~min}$ prior to injection to allow the drug to warm to room temperature. DAC- $\beta$ should not be placed back into a refrigerator after it has reached room temperature. Missed doses should not be given $>2$ weeks after they are due, with the assumption that the previously planned subsequent injection will remain on the same date [56].

\section{Pharmacokinetics}

The pharmacokinetics of DAC- $\beta$ have been investigated in both healthy controls [62] and patients with MS, and were found to be similar in both populations $[63,64]$. DAC- $\beta$ has a half-life of 21 days, and a median $T_{\max }$ of 5 to 7 days. It undergoes catabolism similar to that that of endogenous $\mathrm{IgG}$ proteins. Monthly (every 4 weeks) dosing resulted in achievement of steady state by the fourth dose [63]. Additionally, a larger study of 17,139 patients by Diao et al. [64] demonstrated that the pharmacokinetics of DAC- $\beta$ did not change with age, sex, or baseline T-cell (CD4+/CD25+) count. No significant drug interactions were found in reported testing [56]. Lymphocyte counts were found to return to pretreatment levels between 8 and 12 weeks after cessation of DAC- $\beta$ [56].

\section{Laboratory Monitoring}

Biogen and AbbVie require patients who receive DAC- $\beta$ enroll in their REMS program. Required baseline testing includes liver function testing, tuberculosis screening (purified protein derivative or QuantiFERON testing), and hepatitis B and $\mathrm{C}$ screening. Following baseline testing, monitoring requirements include monthly liver function testing while on DAC- $\beta$. Additionally, following discontinuation of DAC- $\beta$, it is recommended to obtain monthly liver function testing until 6 months after the last dose. Additionally, if a patient develops signs or symptoms concerning for underlying hepatic dysfunction, such as nausea, vomiting, abdominal pain, fatigue, anorexia, or jaundice, prompt assessment of liver function is recommended.

\section{Medical and Financial Support}

Importantly, given the rising cost of MS disease-modifying therapy, Biogen and AbbVie offer a program called AboveMS ${ }^{\mathrm{TM}}$ in which patients on DAC- $\beta$ are connected to nurse educators, support coordinators, and the peer community. Additionally, there is a patient-assistance program involving both $\$ 0$ Copay and free drug services for patients within the AboveMS ${ }^{\mathrm{TM}}$ program.

\section{Management of Adverse Effects}

As discussed in the previous section, adverse effects of concern with daclizumab include liver function testing abnormalities, cutaneous reactions, and other immune-mediated side effects.

As per DAC- $\beta$ 's prescribing information, if AST/ALT are $>5$ times the ULN, or if total bilirubin is $>2$ times the ULN, or if AST/ALT are $\geq 3$ but $<5$ times the ULN and total bilirubin is $>1.5$ but $<2$ times the ULN, active management should be initiated. DAC- $\beta$ treatment should be interrupted while alternative causes of abnormal laboratory values can be investigated; if no alternative etiologies are found, DAC- $\beta$ should be discontinued. If other etiologies are identified, a provider should consider re-initiation of DAC- $\beta$ when the AST and ALT have returned to $<2$ times the ULN and the total bilirubin is $\leq$ ULN [56]. Importantly, a provider should consider specialty evaluation if other causes of liver function abnormalities are suspected or if elevation of AST/ALT is prolonged. If autoimmune hepatitis is suspected, immediate discontinuation of DAC- $\beta$ and referral to a specialist is recommended, as a patient may require systemic corticosteroids or other immunosuppression, possibly long term.

Regarding cutaneous adverse effects, if a patient develops severe or diffuse rash, urgent evaluation by a dermatologist is recommended. Treatment with topical or systemic corticosteroids may be warranted, and it is important to evaluate any skin changes prior to the next dose of DAC- $\beta$. Patients with pre-existing psoriasis or eczema may experience worsening of these conditions on DAC- $\beta$.

There was also an increased rate of lymphadenopathy in patients receiving DAC- $\beta$ in clinical trials, as mentioned above. Most cases resolved spontaneously over a mean of 
3 months, but some led to diagnostic biopsies that demonstrated reactive or inflammatory processes or benign, inactive lymph nodes; no malignancy was reported [52]. Providers should use their judgment and consider specialty evaluation for biopsy when needed [56]. Noninfectious colitis was also reported in clinical trials, and development of symptoms concerning for colitis while on DAC- $\beta$ warrants urgent referral to gastroenterology. Other various immune-mediated disorders were seen rarely in patients taking DAC- $\beta$ in clinical trials, but suspicion of these conditions should warrant specialist referral for further evaluation.

\section{Immunogenicity}

Daclizumab has the potential for development of antidrug and neutralizing antibodies, as is commonly noted with use of monoclonal antibodies and other biologic agents. In the SELECT trial, daclizumab neutralizing antibodies were present in 6/417 (1\%) of patients (5 in DAC- $\beta 150 \mathrm{mg}$ and 1 in $300 \mathrm{mg}$ groups) at week 24 [48]. These antibodies were transient in some patients, as at week 52, only 1 patient in each DAC- $\beta$ group was noted to have neutralizing antibodies. As per the DAC- $\beta$ prescribing information, patients in the DECIDE study were monitored regularly for antidaclizumab antibodies, and it was noted that antidrug and neutralizing antibodies developed primarily during the first year of treatment and were mostly transient [56]. Nineteen percent of patients developed antidrug antibodies, and $8 \%$ of patients developed neutralizing antibodies. With neutralizing antibodies, it was reported that DAC- $\beta$ clearance increased by $19 \%$, but there was no relationship observed between neutralizing or antidrug antibodies and clinical effectiveness or adverse events $[56,63]$.

\section{Vaccination Guidelines}

Vaccination with live vaccines is not recommended during or 4 months after discontinuation of treatment with DAC- $\beta$. Therefore, it is recommended that patients receive the varicella zoster vaccine prior to initiating therapy with $D A C-\beta$ if it is indicated.

\section{Future Work and Considerations}

Daclizumab has unique and multiple mechanisms of action distinct from other immunotherapies for MS, including increases in number and function of CD56 bright NK cells, inhibition of LTIs, and inhibition of antigen presentation. All of these mechanisms are important in the pathogenesis of MS [3].

Importantly, immunoregulation in patients with MS on therapy with daclizumab has not been associated with PML
Table 5 Existing anti-CD25 monoclonal antibodies (mAbs)

\begin{tabular}{|c|c|c|c|}
\hline Generic name & Trade name & Source & Indications \\
\hline Daclizumab IV & Zenapax $^{\mathrm{TM}}$ & $\begin{array}{l}\text { Humanized } \\
\mathrm{mAb}\end{array}$ & $\begin{array}{l}\text { No longer } \\
\text { manufactured }\end{array}$ \\
\hline Basiliximab IV & Simulect ${ }^{\mathrm{TM}}$ & Chimeric $\mathrm{mAb}$ & $\begin{array}{l}\text { Not formally tested in } \\
\text { MS }\end{array}$ \\
\hline $\begin{array}{l}\text { Daclizumab- } \beta \\
\quad \text { SQ }\end{array}$ & Zinbryta $^{\mathrm{TM}}$ & $\begin{array}{l}\text { Humanized } \\
\mathrm{mAb}\end{array}$ & Approved for RRMS \\
\hline
\end{tabular}

$\mathrm{IV}=$ intravenous; $\mathrm{SQ}=$ subcutaneous; $\mathrm{MS}$ = multiple sclerosis; $\mathrm{RRMS}=$ relapsing-remitting $\mathrm{MS}$

in the clinical trials to date. However, there is the potential for significant liver enzyme elevation and autoimmune hepatitis to develop in patients on daclizumab therapy. Monitoring for rashes and early assessment and management is important. Occasionally, rashes reach the level of significant adverse events and require treatment with intravenous corticosteroids and antihistamines. Pretreatment assessment for tuberculosis and viral hepatitis is recommended.

\section{Daclizumab Formulations}

As mentioned above, the various studies investigating the effectiveness and safety of daclizumab used different forms of the drug. Specifically, the earlier studies in MS utilized intravenous daclizumab [28], the CHOICE study used SQ1 formulation [47], and the SELECT and DECIDE studies used the daclizumab- $\beta$ (SQ2, DAC-HYP; Zinbryta ${ }^{\mathrm{TM}}$ ) formulation $[48,51]$. Owing to changes in the formulations and the varying durations and numbers of patients on the particular therapies, it may be difficult to determine advantages of one versus the other daclizumab preparations. Nonetheless exploration of the routes of administration and comparison of the 3 forms of daclizumab would be of considerable interest.

Table 6 Strategies for development of anti-CD25 monoclonal antibody $(\mathrm{mAb})$

\begin{tabular}{ll}
\hline Strategy & Potential benefit for anti-CD25 mAb \\
\hline 1) Develop a human MAb & Less immunogenic \\
2) Change IgG isotype & Modulation of Fc functions \\
3) Change epitope & Alter binding and/or IL-2 blockade \\
4) Change affinity & Change kinetics and duration of \\
& binding \\
5) Change glycosylation & Alter ADCC or CDC function \\
6) Prepare Fab or Fab'2 & Eliminate Fc functions and \\
fragments & cytotoxicity \\
\hline
\end{tabular}

$\mathrm{Fc}=$ fragment crystallizable region; $\mathrm{IL}=$ interleukin $; \mathrm{ADCC}=$ antibody dependent cell-mediated cytotoxicity; $\mathrm{CDC}=$ complement-dependent cytotoxicity; Fab $=$ fragment antigen binding 


\section{Daclizumab and New Directions for Anti-CD25 MAb Therapy}

Three anti-CD25 specific mAbs have approved by the FDA: intravenous daclizumab, intravenous basilixumab, and daclizumab- $\beta$. Their properties are described in Table 5.

Further study of dose and pharmacokinetics could be important to reach optimal efficacy for the anti-CD25 mAbs [51, 52]. However, there is considerable opportunity to study the properties of anti-CD25 mAbs. Strategies commonly utilized in the design of mAbs could be applied and have been implemented with anti-CD20 and other mAbs, as described in Table $6[1,65]$.

While these manipulations of anti-CD25 mAbs could favorably alter the function, they might also decrease or increase adverse effects for one or another of the applications to human diseases, whether autoimmune or neoplastic [66]. Reduction in side effects and improved efficacy could be achieved. $\mathrm{mAbs}$ are important therapeutic agents for initially targeting cytokines or their receptors. The evolution of treatments may proceed to small molecules that are agonists or antagonists for a ligand such as IL-2.

Identifying IL-2 and IL-2R activation may allow for therapeutics downstream of the initial binding of the cytokine to the receptor [31]. The elaboration of the effects of anti-CD25 on both the innate and adaptive immune responses and their interactions directly aids our knowledge of MS pathogenesis and provides new avenues for immunotherapeutics [3].

Acknowledgements We thank the Department of Veterans Affairs, the National Institutes of Health, the University of Utah, the Cumming Foundation, and Protein Design Laboratories for research support for preclinical studies, as well as early clinical trials (JR); we thank AbbVie Biotherapeutics and Biogen (JR) for their support for participation in clinical trials; this study was also supported by a fellowship award from National Multiple Sclerosis Society (LB). The authors appreciate the assistance of Dr. Noel Carlson in preparation of the figures for this manuscript.

\section{References}

1. Therapeutic Monoclonal Antibodies: From the bench to the clinic. Hoboken, New Jersey: John Wiley \& Sons, Inc; 2009.

2. Martin R. Anti-CD25 (daclizumab) monoclonal antibody therapy in relapsing-remitting multiple sclerosis. Clin Immunol 2012;142(1):9-14.

3. Bielekova B. Daclizumab therapy for multiple sclerosis. Neurotherapeutics 2013;10(1):55-67.

4. Sheridan JP, Robinson RR, Rose JW. Daclizumab, an IL-2 modulating antibody for treatment of multiple sclerosis. Expert Rev Clin Pharmacol 2014;7(1):9-19.

5. Liao W, Lin JX, Leonard WJ. IL-2 family cytokines: new insights into the complex roles of IL-2 as a broad regulator of T helper cell differentiation. Curr Opin Immunol 2011;23(5):598-604.

6. Klatzmann D, Abbas AK. The promise of low-dose interleukin-2 therapy for autoimmune and inflammatory diseases. Nat Rev Immunol 2015;15(5):283-294.
7. Kim JM, Rasmussen JP, Rudensky AY. Regulatory T cells prevent catastrophic autoimmunity throughout the lifespan of mice. Nat Immunol 2007;8(2):191-197.

8. Malek TR. The biology of interleukin-2. Ann Rev Immunol 2008;26:453-479.

9. Milo RS, Stüve O. Spotlight on daclizumab: its potential in the treatment of multiple sclerosis. Degen Neurol Neuromusc Dis 2016;6:95-109.

10. Waldmann TA, Kozak RW, Tsudo M, Oh-ishi T, Bongiovanni KF, Goldman CK. IL-2 receptors in adult T-cell leukemia: a target for immunotherapy. Haematol Blood Transfus 1987;31:110-115.

11. Waldmann TA, Longo DL, Leonard WJ, et al. Interleukin 2 receptor (Tac antigen) expression in HTLV-I-associated adult T-cell leukemia. Cancer Res 1985;45(9 Suppl.):4559s-4562s.

12. Waldmann TA, O'Shea J. The use of antibodies against the IL-2 receptor in transplantation. Curr Opin Immunol 1998;10(5):507512.

13. Waldmann TA. Anti-Tac (daclizumab, Zenapax) in the treatment of leukemia, autoimmune diseases, and in the prevention of allograft rejection: a 25-year personal odyssey. J Clin Immunol 2007;27(1): $1-18$.

14. Waldmann TA. Daclizumab (anti-Tac, Zenapax) in the treatment of leukemia/lymphoma. Oncogene 2007;26(25):3699-3703.

15. Leonard WJ. Cytokines and immunodeficiency diseases. Nat Rev Immunol 2001;1(3):200-208.

16. Rose JW, Foley JF, Carlson NG. Monoclonal antibody treatments for multiple sclerosis. Curr Treat Options Neurol 2009;11(3):211220.

17. Rose JW, Lorberboum-Galski H, Fitzgerald D, et al. Chimeric cytotoxin IL2-PE40 inhibits relapsing experimental allergic encephalomyelitis. J Neuroimmunol 1991;32(3):209-217.

18. Phillips SM, Bhopale MK, Constantinescu CS, et al. Effect of DAB(389)IL-2 immunotoxin on the course of experimental autoimmune encephalomyelitis in Lewis rats. J Neurol Sci 2007;263(12):59-69.

19. Jones PT, Dear PH, Foote J, Neuberger MS, Winter G. Replacing the complementarity-determining regions in a human antibody with those from a mouse. Nature 1986;321(6069):522-525.

20. Queen C, Schneider WP, Selick HE, et al. A humanized antibody that binds to the interleukin 2 receptor. Proc Natl Acad Sci U S A 1989;86(24):10029-10033.

21. Vincenti F, Kirkman R, Light S, et al. Interleukin-2-receptor blockade with daclizumab to prevent acute rejection in renal transplantation. Daclizumab Triple Therapy Study Group. N Engl J Med 1998;338(3):161-165.

22. Nussenblatt RB, Fortin E, Schiffman RP et al. Treatment of noninfectious intermediate and posterior uveitis with the humanized antiTac mAb: a phase I/II clinical trial. Proc Natl Acad Sci U S A 1999;96(13):7462-7466.

23. Nussenblatt RB, Peterson JS, Foster CS, et al. Initial evaluation of subcutaneous daclizumab treatments for noninfectious uveitis: a multicenter noncomparative interventional case series. Ophthalmology 2005;112(5):764-770.

24. Nussenblatt RB, Thompson DJ, Li Z, et al. Humanized antiinterleukin-2 (IL-2) receptor alpha therapy: long-term results in uveitis patients and preliminary safety and activity data for establishing parameters for subcutaneous administration. J Autoimmun 2003;21(3):283-293.

25. Lehky TJ, Levin MC, Kubota R, et al. Reduction in HTLV-I proviral load and spontaneous lymphoproliferation in HTLV-I-associated myelopathy/tropical spastic paraparesis patients treated with humanized anti-Tac. Ann Neurol 1998;44(6):942-947.

26. Bielekova B, Howard T, Packer AN, et al. Effect of anti-CD25 antibody daclizumab in the inhibition of inflammation and stabilization of disease progression in multiple sclerosis. Arch Neurol 2009;66(4):483-489. 
27. Rose JW, Watt HE, White AT, Carlson NG. Treatment of multiple sclerosis with an anti-interleukin-2 receptor monoclonal antibody. Ann Neurol 2004;56(6):864-867.

28. Rose JW, Burns JB, Bjorklund J, Klein J, Watt HE, Carlson NG. Daclizumab phase II trial in relapsing and remitting multiple sclerosis: MRI and clinical results. Neurology 2007;69(8):785-789.

29. Rojas MA, Carlson NG, Miller TL, Rose JW. Long-term daclizumab therapy in relapsing-remitting multiple sclerosis. Ther Adv Neurol Disord 2009;2(5):291-297.

30. Oh J, Saidha S, Cortese I, et al. Daclizumab-induced adverse events in multiple organ systems in multiple sclerosis. Neurology 2014;82(11):984-988.

31. Pfender N, Martin R. Daclizumab (anti-CD25) in multiple sclerosis. Exp Neurol 2014;262 Pt A:44-51.

32. Wiendl HG, C.C. Modulation of IL-2R $\alpha$ with daclizumab for treatment of multiple sclerosis. Nat Rev Neurol 2013;9(7):394-404.

33. Bielekova B, Catalfamo M, Reichert-Scrivner S, et al. Regulatory CD56(bright) natural killer cells mediate immunomodulatory effects of IL-2Ralpha-targeted therapy (daclizumab) in multiple sclerosis. Proc Natl Acad Sci U S A 2006;103(15):5941-5946.

34. Elkins J, Sheridan J, Amaravadi L, et al. CD56(bright) natural killer cells and response to daclizumab HYP in relapsing-remitting MS. Neurology 2015;2(2):e65.

35. Chanvillard C, Jacolik RF, Infante-Duarte C, Nayak RC. The role of natural killer cells in multiple sclerosis and their therapeutic implications. Front Immunol 2013;4:63.

36. Martin JF, Perry JS, Jakhete NR, Wang X, Bielekova B. An IL-2 paradox: blocking CD25 on T cells induces IL-2-driven activation of CD56(bright) NK cells. J Immunol 2010;185(2):1311-1320.

37. Huss DJ, Mehta DS, Sharma A, et al. In vivo maintenance of human regulatory T cells during CD25 blockade. J Immunol 2015;194(1):84-92.

38. Oh U, Blevins G, Griffith CR et al. Regulatory T cells are reduced during anti-CD25 antibody treatment of multiple sclerosis. Arch Neurol 2009;66(4):471-479.

39. Jiang W, Chai NR, Maric D, Bielekova B. Unexpected role for granzyme $\mathrm{K}$ in CD56bright NK cell-mediated immunoregulation of multiple sclerosis. J Immunol 2011;187(2):781-790.

40. Wuest SC, Edwan JH, Martin JF, et al. A role for interleukin-2 trans-presentation in dendritic cell-mediated $\mathrm{T}$ cell activation in humans, as revealed by daclizumab therapy. Nat Med 2011;17(5): 604-609.

41. Schluns KS. Window of opportunity for daclizumab. Nat Med 2011:5: 545-547.

42. Yu A, Zhu L, Altman NH, Malek TR. A low interleukin-2 receptor signaling threshold supports the development and homeostasis of T regulatory cells. Immunity 2009;30(2):204-217.

43. Snyder JT, Shen J, Azmi H, Hou J, Fowler DH, Ragheb JA. Direct inhibition of CD40L expression can contribute to the clinical efficacy of daclizumab independently of its effects on cell division and Th1/Th2 cytokine production. Blood 2007;109(12):5399-5406.

44. Perry JS, Han S, Xu Q, et al. Inhibition of LTi cell development by $\mathrm{CD} 25$ blockade is associated with decreased intrathecal inflammation in multiple sclerosis. Sci Transl Med 2012;4(145):145ra06.

45. Rose JW. Anti-CD25 immunotherapy: regulating the regulators. Sci Transl Med 2012;4(145):145fs25.

46. Gillard GO, Saenz SA, Huss DJ, Fontenot JD. Circulating innate lymphoid cells are unchanged in response to DAC HYP therapy. J Neuroimmunol 2016;294:41-45.

47. Wynn D, Kaufman M, Montalban X, et al. Daclizumab in active relapsing multiple sclerosis (CHOICE study): a phase 2 , randomised, double-blind, placebo-controlled, add-on trial with interferon beta. Lancet Neurol 2010;9(4):381-390.

48. Gold R, Giovannoni G, Selmaj K, et al. Daclizumab high-yield process in relapsing-remitting multiple sclerosis (SELECT): a randomised, double-blind, placebo-controlled trial. Lancet 2013;381(9884):2167-2175.
49. Giovannoni G, Gold R, Selmaj K, et al. Daclizumab high-yield process in relapsing-remitting multiple sclerosis (SELECTION): a multicentre, randomised, double-blind extension trial. Lancet Neurol 2014;13(5):472-481.

50. Gold R, Radue EW, Giovannoni G, et al. Safety and efficacy of daclizumab in relapsing-remitting multiple sclerosis: 3-year results from the SELECTED open-label extension study. BMC Neurol 2016;16:117.

51. Kappos L, Wiendl H, Selmaj K, et al. Daclizumab HYP versus Interferon Beta-1a in Relapsing Multiple Sclerosis. N Engl J Med 2015;373(15):1418-1428

52. Giovannoni G, Kappos L, Gold R, et al. Safety and tolerability profile of daclizumab in patients with relapsing-remitting multiple sclerosis: an integrated analysis of clinical studies. Mult Scler Relat Disord 2016;9:36-46.

53. Cortese I, Ohayon J, Fenton K, et al. Cutaneous adverse events in multiple sclerosis patients treated with daclizumab. Neurology 2016;86(9):847-855.

54. Mehta LR, Rose JW. Recurrent granuloma annulare during treatment with daclizumab. Mult Scler 2009;4:527-528.

55. Krueger JG, Kircik L, Hougeir F, et al. Cutaneous adverse events in the randomized, double-blind, active-comparator DECIDE study of daclizumab high-yield process versus intramuscular interferon beta1a in relapsing-remitting multiple sclerosis. Adv Ther 2016;33(7): 1231-1245.

56. Zinbryta(R) [package insert]. Biogen, Inc., Cambridge, MA; May 2016. Available at: https://www.zinbryta.com/content/dam/ commercial/multiple-sclerosis/zinbryta/pat/en us/pdfs/zinbrytaprescribing-information.pdf. Accessed March 1, 2017.

57. Gorman MP, Tillema JM, Ciliax AM, Guttmann CR, Chitnis T. Daclizumab use in patients with pediatric multiple sclerosis. Arch Neurol 2012;69(1):78-81.

58. Cohen JA, Barkhof F, Comi G, et al. Oral fingolimod or intramuscular interferon for relapsing multiple sclerosis. N Engl J Med 2010;362(5):402-415.

59. Hauser SL, Bar-Or A, Comi G, et al. Ocrelizumab versus interferon beta-1a in relapsing multiple sclerosis. N Engl J Med 2017;376(3): 221-234.

60. Cohan S, Kappos L, Wiendl H, et al. Efficacy of daclizumab versus intramuscular interferon beta-1a on disability progression across patient demographic and disease activity subgroups in DECIDE. Mult Scler 2017 (in press)

61. Rose JWG, G.; Wiendl, H.; Gold, R.; Havrdova, E.; Kappos, L.; Selmaj, K.W.; Zhao, J.; Riester, K.; Tsao L.C.; Greenberg, S.J. Consistent efficacy of daclizumab beta across patient demographic and disease activity subgroups in patients with relapsing-remitting multiple sclerosis. Mult Scler Relat Disord. 2017;17:32-40.

62. Othman AA, Tran JQ, Tang MT, Dutta S. Population pharmacokinetics of daclizumab high-yield process in healthy volunteers: integrated analysis of intravenous and subcutaneous, single- and multiple-dose administration. Clin Pharmacokinet 2014;53(10): 907-918.

63. Tran JQ, Othman AA, Mikulskis A, Wolstencroft P, Elkins J. Pharmacokinetics of daclizumab high-yield process with repeated administration of the clinical subcutaneous regimen in patients with relapsing-remitting multiple sclerosis. Clin Pharmacol 2016;8:9-13.

64. Diao L, Hang Y, Othman AA, Nestorov I, Tran JQ. Population pharmacokinetics of daclizumab high-yield process in healthy volunteers and subjects with multiple sclerosis: analysis of phase I-III clinical trials. Clin Pharmacokineti 2016;55(8):943-955.

65. Cang S, Mukhi N, Wang K, Liu D. Novel CD20 monoclonal antibodies for lymphoma therapy. J Hematol Oncol 2012;5:64.

66. Mitchell DA, Cui X, Schmittling RJ, et al. Monoclonal antibody blockade of IL-2 receptor alpha during lymphopenia selectively depletes regulatory $\mathrm{T}$ cells in mice and humans. Blood 2011;118(11):3003-3012. 